\title{
Aerated Underbalance Drilling Screening Assessment at "X" Geothermal Field
}

\author{
Ariya Dwinanto a and Sudjati Rachmata \\ ${ }^{a}$ Geothermal Lab. Gd. Teknik Perminyakan FTTM - Institut Teknologi Bandung Jalan Ganesa 10, Bandung 40132 Indonesia
}

\begin{abstract}
Fault network is a challenging problem for geothermal drilling operations. Formation fluid contains high temperature production fluid which can reach $>225^{\circ} \mathrm{C}$ on high enthalpy system. The other consequences is that almost all fault network has low pressure or subnormal pressure. This low pressure results to a loss circulation problem. This low pressure can even go lower if the geothermal field has been exploited for a long period. A miss reservoir management, that do not re-inject sufficient amount of fluid, will cause the reservoir pressure go lower. Another problem in Indonesia is the conservation area which almost all high enthalpy geothermal system exist. The pay zone that is beneath the conservation area must be reached by directional drilling as a solution. High temperature fluid, low formation pressure and conservation areas are problems for geothermal drilling. To overcome these problems, underbalance drilling method has an advantage dealing with low pressure reservoir.

This paper introduces a way to screen the underbalance drilling method on a certain field. This study will help the quantitative and qualitative decision whether the underbalance drilling is feasible or not. The first phase qualitative decision is based on wellbore stability, loss circulation, reservoir damage, stuck pipe incident, hard drilling and cost benefit. Then it will go to the drilling fluid decision. And at the end as a quantitative decision for constructing a feasible bottom hole pressure window area with some hole cleaning assessment. Underbalance drilling assessment will be studied on field " $\mathrm{X}$ " at one of Indonesia's geothermal field. The screening of " $\mathrm{X}$ " geothermal field comes with conclusions that it has an opportunity underbalance drilling can be implemented with vertical aerated drilling wells on spesific gas and liquid flow rates.
\end{abstract}

Keywords: Geothermal, underbalance drilling, aerated drilling

\section{Introduction}

Indonesia have good resources of convective hydrothermal geothermal system, which heat transfers mostly on fluid media. Those fluid media exist on a vapor dominated or liquid dominated phase. Fluid moves on fault network that is the main target of drilling in geothermal. Fault network gives the conduit facility for recharge fluid to flow in to the heat source as recharge zone and fault network also gives the conduit facility for formation fluid to emerge to the surface as up flow / outflow zone.

Fault network is a challenging problem for drilling operations. Formation fluid contains high temperature production fluid which can reach $>225^{\circ} \mathrm{C}$ on high enthalpy system. The other consequecies is that almost all fault network has low pressure or subnormal pressure (Hole, 2006). Figure 1 describes the low pressure phenomena. This low pressure results to a loss circulation problem. High temperature fluid and low fomation pressure are main problems for geothermal drilling.

Conventional overbalance drilling has weaknesses if considering low pressure reservoir. Drilling fluid pressure is intentionally higher than pore pressure. As a result, loss circulation becomes a common problem. Underbalance drilling method has an advantage dealing with low pressure reservoir. Loss circulation problem can be mitigated by the drilling fluid pressure which is intentionally lower than the reservoir pore pressure.

Underbalance drilling with it's advantages and weaknesses has to be studied. This study will help the quantitative and qualitative decision whether the underbalance drilling is feasible or not. It will help to decide which drilling fluid is compatible. This study will construct a feasible bottom hole pressure window area with some hole cleaning assessment. 


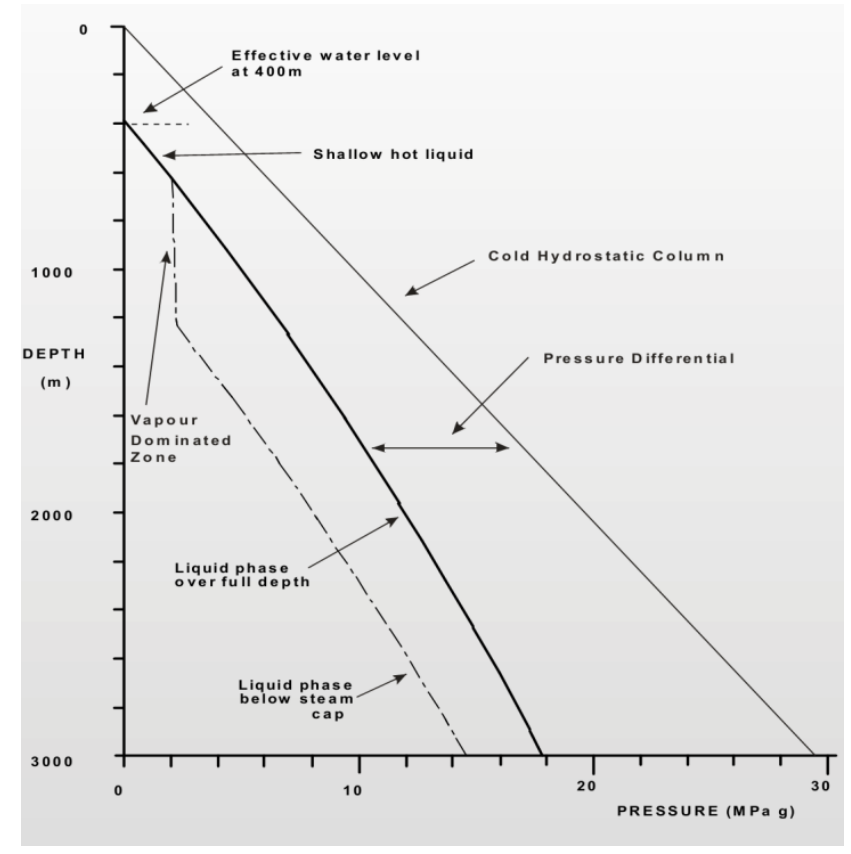

Fig. 1 Geothemal low pressure reservoirs (Hole, 2006)

\section{Methodology}

The two first process from figure 2 are processess needed for process three input data. Process reservoir characterization determines the well type, based on production fluid and reservoir domination type. Process casing diameter feasibility with wellbore stimulation determines the casing diameter. These two process will give the fluid fraction and production casing diameter (big hole or small hole) input data.

Process underbalance screening includes decisions whether underbalance has an opportunity or not and drilling fluid selection. Underbalance screening is studied on literature and is compared with the actual field offset drilling events. Al-ajmi (2003) gives a great method for the process. Unfortunately some of the screening process need expert judgements. These subjective judgements will be mitigated by some graphic based on Indonesia's geothermal datas. Thus people with less experiences may conduct for same results.

After the debit approximation is determined, we can go to the next step. Bottom hole pressure will be counted. Bottom hole pressure will effect the drilling fluid properties. And the drilling fluid properties will effect the bottom hole pressure, thus iterations are needed. Lyon et. al. (2009) describe underbalance techniques to determine bottom hole pressure.

One of important parts of drilling operation is the circulation system. The fluid has to guaranteed to lift cuttings up to the surface. Lifting cutting often known as hole cleaning process. In an effective hole cleaning process, there is a minimum velocity that should be implemented. The minimum velocity will be counted using Lyon's et. al. (2009) method. Bottom hole pressure and hole cleaning process will give two boundary criteria needed to conduct bottom hole pressure window area.

To conduct the bottom hole pressure window, we have to study the boundary. The boundary limitation is considered from : bottom hole pressure, liquid phase drilling fluid flow rate, vapor phase drilling fluid flow rate, motor pump capacity, reservoir pressure drop and hole cleaning assessment. These consideration will describe the bottom hole pressure window area to underbalance drilling.

\subsection{Reservoir characterization}

Each reservoir has it's own characteristic. Geothermal reservoir can be distinguish by the 
production fluids. There are : water dominated reservoir or vapor dominated reservoir. Each of the reservoir need to be indentified. Using boiling per depth graphic which is modified from pressure and temperature surveys, a well is considered single phase or double phase. Then each of the well are gathered to give a conclusion about what is the reservoir type.

\subsection{Casing diameter feasibility}

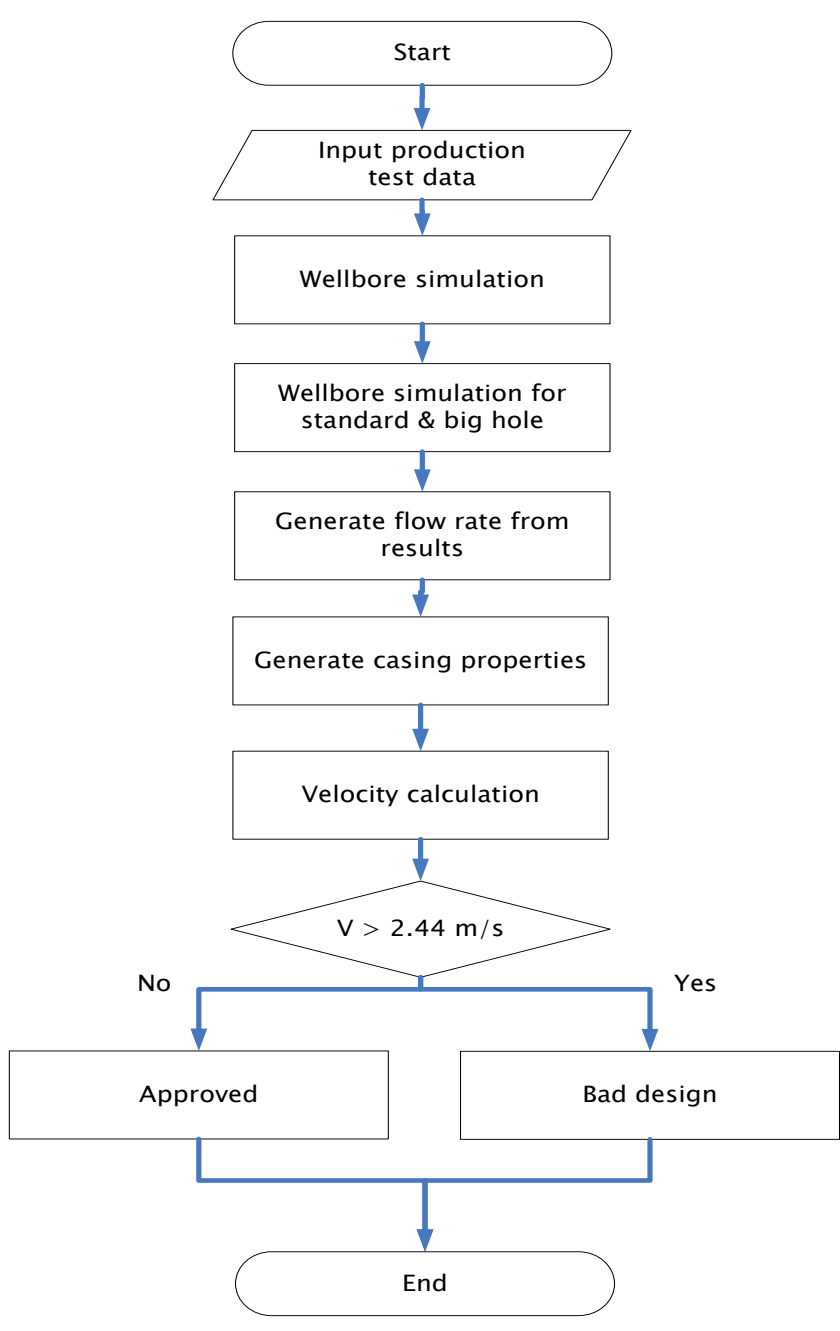

Fig. 3 Casing feasibility flow chart

To compute wellbore simulations, a set of production test has to be known. Then a wellbore simulation may be conducted to achieve a simmillar behaviour such as known on the datas. Wellbore simulation gives a prediction of the well ability (productivity index / PI) to produce at a certain debit with a specific pressure. The production simulation needs the fluid enthalpy that describe the quality of the production fluid. These data is simulated to conduct the well pressure behaviour as similar as possible. Afterward a standard hole and a big hole simulation based on the productivity index prediction can be conducted. These processes will generate flow rate datas which is usefull for the next step.

Analysing production casing geometry will give an area that a production fluid may pass through. Casing catalogue will give various of casing inner areas. Casing that had been choosen then are computed to give a velocity for a flow rate generated from wellbore stimulations. Equation 1 generates velocity for certain value of flow rate.

$$
\text { V } \frac{Q}{\pi \cdot I D^{2}}
$$

An upper velocity limit should be considered a max limit. As above this, noise and erosion will take place. Lyle (1947) had predicted the upper limit for a one phase liquid flow in a steel pipe tube which is $2.44 \mathrm{~m} / \mathrm{s}$. Equation 1 with process number one until five give a velocity prediction. Thus will give a clue about what diameter should be implemented.

\section{Underbalance screening process}

Underbalance candidate screening process is a broad assessment. It will need a great span of data and a great comparison for it's litrature riview. Al-ajmi (2003) had been researching and studying many literature. He sugested two screening process subsequently : underbalance screening and drilling fluid screening process. He came with a sequence of methodology that can be used on mainly oil and gas reservoir. With some adjustment for geothermal condition, this method can be a powerfull method to decide to go with underbalance method or not. Then after a yes decision is made, it goes thru a drilling fluid assessment which will guide user to use proper drilling fluid for such reservoir. The sequence of underbalance assessment will be explained by subject briefly. All of the entitiy 
process on the flowchart are not mandatory, it depends on the flowchart guide that is clear on figure 4 .

\subsection{Stable rock anticipated}

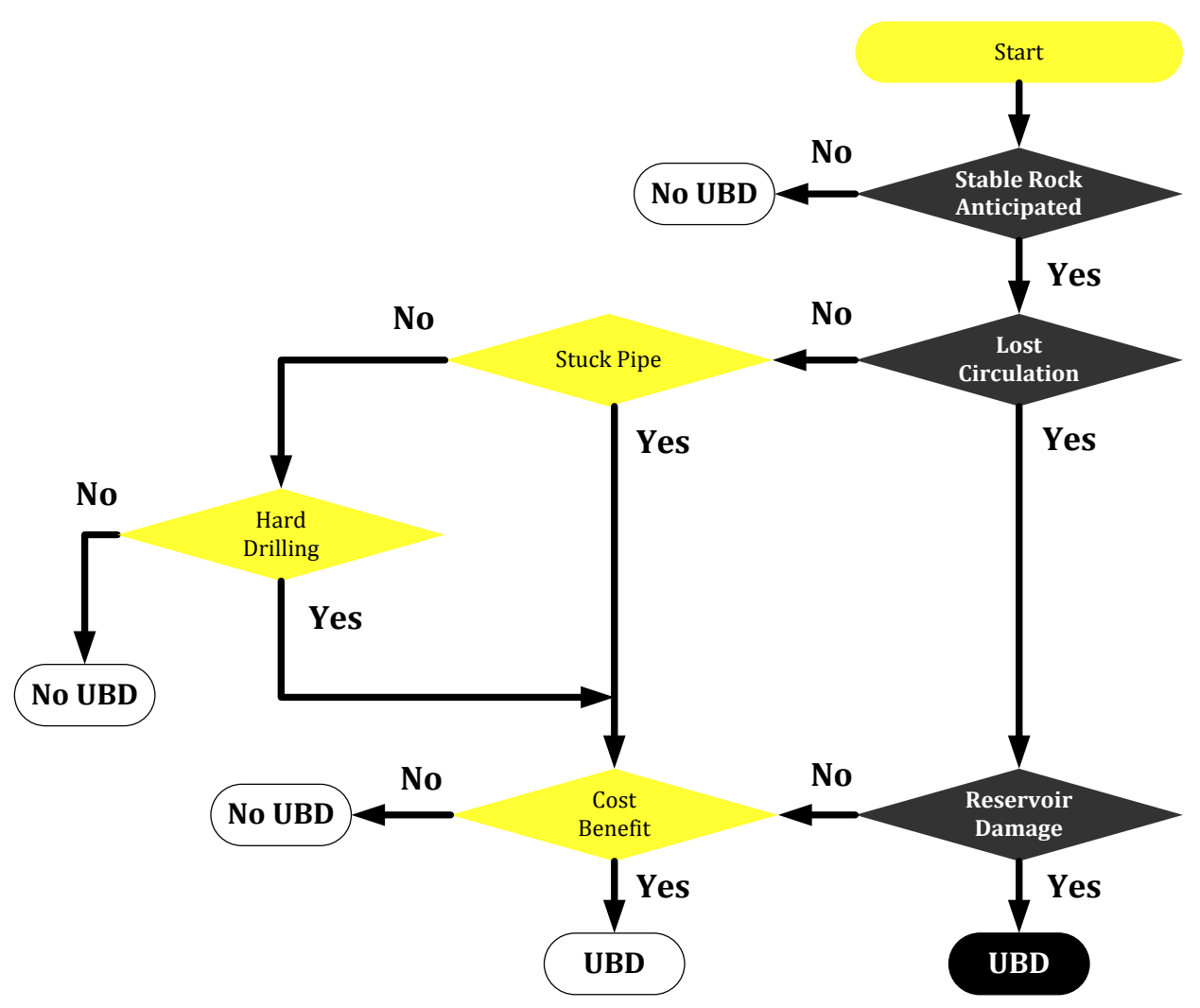

Fig. 4 Underbalance decision flow chart (Al-ajmi, 2003)
Wellbore stability is important. The ability of the formation to support and withstand the hole will be good if the hole does not cave in, collapse or getting narrower. Those problems are going to cause issue such as pipe sticking or even drilling failure which can incentifies drilling non performing time. 


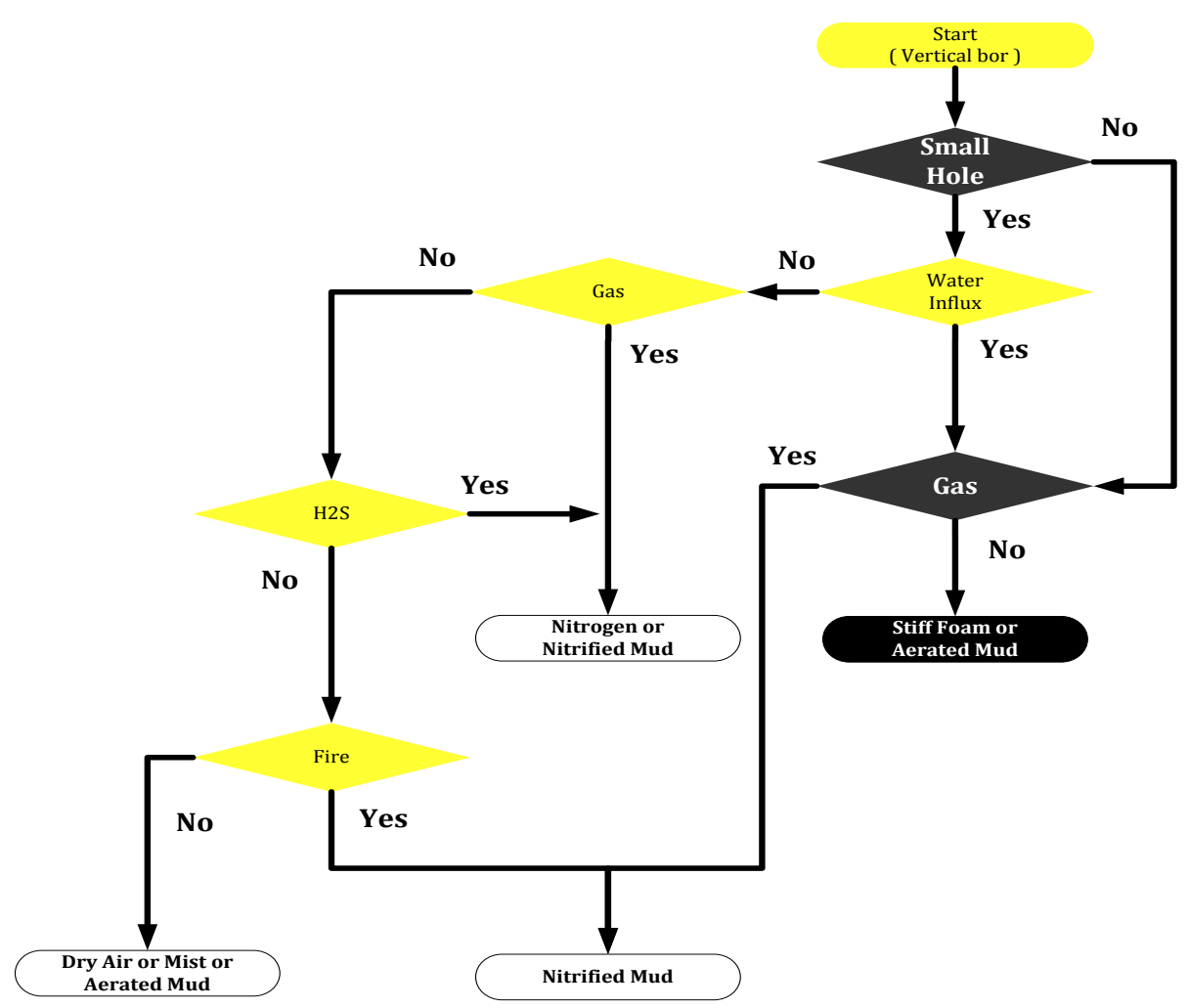

Fig. 5 Drilling fluid decision on vertical wellbore flow chart (Al-ajmi, 2003)

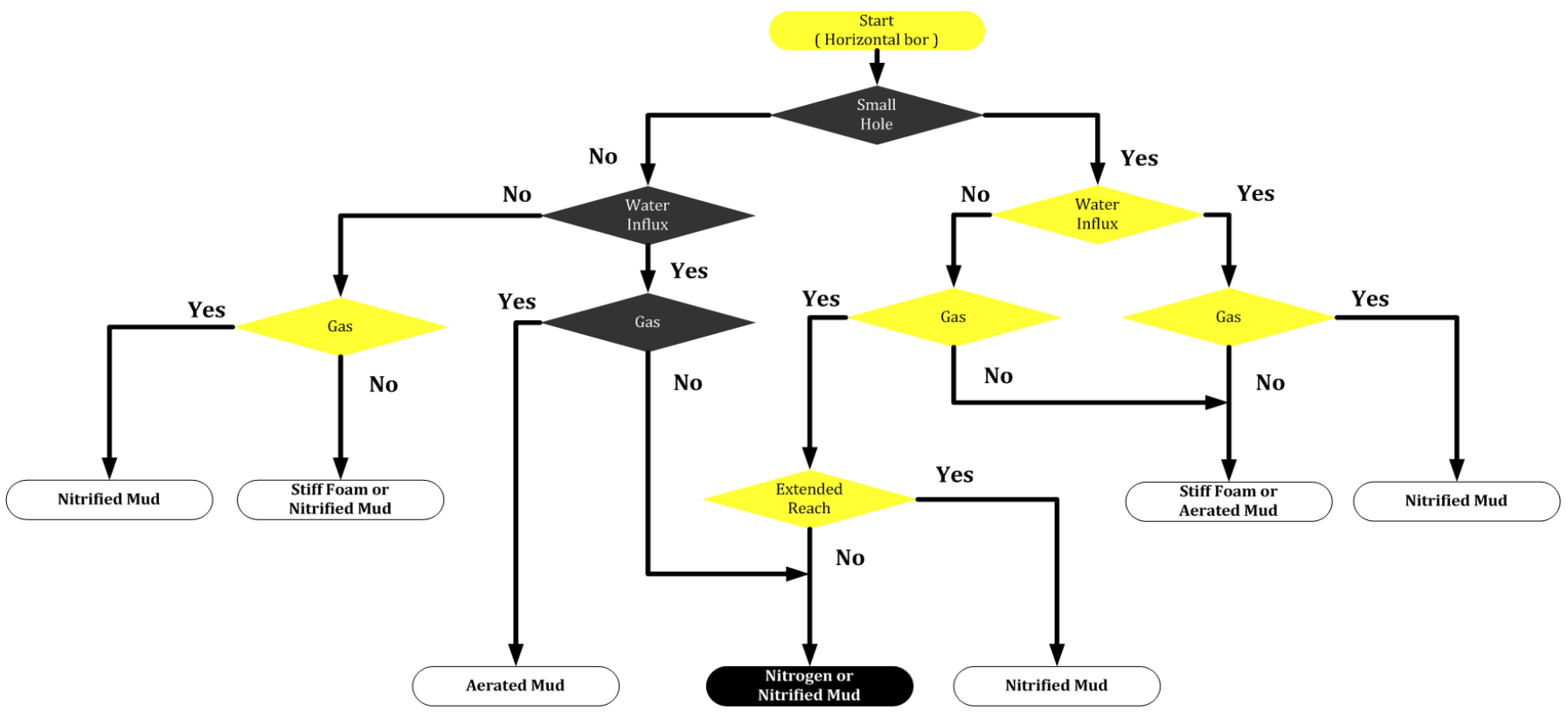

Fig. 6 Drilling fluid decision on horizontal wellbore flow chart (Al-ajmi, 2003) 

factors:

Wellbore instability problems may exist from these

- The formation contains significant amount of water sensitive clays.

- The formation is weak.

Clays that is prone to swelling are clay which are the most water sensitive clays. To determine clay swelling potential, it is assumed that the clay types, volume fractions, and distribution are known. Vitthal et al (1989) introduces clay swelling index. The index given on equation 2, predicts how bad a formation clay can swell.

$$
\Phi_{s} \quad 100 \cdot \frac{I_{S}}{10} . C S
$$

Table 1

Damage indices for pure clays

\begin{tabular}{lcc}
\hline $\begin{array}{c}\text { Clay } \\
\text { component }\end{array}$ & $\begin{array}{c}\text { Swelling Index } \\
\text { (IS) }\end{array}$ & $\begin{array}{c}\text { Fine-migration } \\
\text { Index (IF) }\end{array}$ \\
\hline Montmorillonite & 10 & 10 \\
Chlorite & 1 & 6 \\
Kaolinite & 1 & 6 \\
Illite & 2 & 8 \\
Vermiculite & 5 & 2 \\
\hline
\end{tabular}

Table 2

Distribution correction factors

\begin{tabular}{lcc}
\hline \multicolumn{1}{c}{ Clay distribution } & $\begin{array}{c}\text { Swelling } \\
\text { Factor (CS) }\end{array}$ & $\begin{array}{c}\text { Fine-migration } \\
\text { factor (CF) }\end{array}$ \\
\hline Pore lining & 1 & 0,7 \\
Pore filling & 1 & 1 \\
Pore bridging & 0,5 & 1 \\
Discrete participles & 0 & 0,9 \\
Thin lenses & 0,5 & 0 \\
\hline
\end{tabular}

Prone swelling clays are: montmorillonite, chlorite, kaolinite, illite and vermiculite. Clays react differently when it counter water. The most susceptible clay is montmorillonite, thus it's swelling index indicates value 10 which is the highest swelling index value. Chlorite and kaolinite at the other side give the lowest swelling index value which is 1 . These swelling index are calculated with the clay distribution factor, thus give a swelling potential govern by equation 2 .

There is the upper limit of density so that underbalance drilling can exist and the lower density limit so that the wellbore can with stand the strain to achieve wellbore stability. The lowest limit to be considered for mud weight should be borehole collapse pressure gradient. This borehole collapse pressure gradient is computed by uncontrollable factors: local borehole stress, pore pressure and rock strength conditions. Also controllable factor will help maintaining stability: wellbore fluid pressure. Another consideration is on hole angle. As the hole angle increases, the borehole collapse pressure gradient will decrease. Controllable and uncontrollable factor will effect the lower density limit. (Fuh, 1988)

\subsection{Lost circulation}

Lost circulation is the event when a significant amount of drilling mud is lost to the formation. It occurs when natural, or induced formation openings are large enough to allow mud to pass through. Al-Ajmi (2003) determines a qualitative method to assess lost circulation potential. The lost circulation potential is based on two features on a reservoir which is fractures and vugs. The fracture $\left(I_{F r}\right)$ enhance significant on rock permeability. Vugs $\left(I_{V}\right)$ is a small cavity in a rock or vein, often with mineral lining of different composition from that of the surrounding. It is much narrower if considering spaces in fractures. An index ranging from 1 to 10 for each fractures and vugs is introduced. Other two features which is based on a quantitative estimate to assess lost circulation are The permeability (k) and the porosity $(\phi)$. Equation 3 describe how a lost circulation index can be computed.

$I_{L C} \quad k \cdot \phi \cdot \frac{I_{F r}}{10} \cdot \frac{I_{V}}{10}$

Guidelines which determine lost circulation problems :

- $I_{L C} \geq 5 \%$ have severe lost circulation problems

- $I_{L C}<0.1 \%$ have no lost circulation problems

- $0.1 \%<I_{L C} \leq 5 \%$ have some lossess.

Al-Ajmi (2003) explains that only an expert can use equation 3 . This may limit it's value. Thus to make it more usefull, a fracture graphic based on Indonesia's geothermal well lost circulation events is made. Figure 
12 illustrates that by knowing a average number of lost circulation events on a well or a few well, the fracture index can be generated. Vugs index can be generated from figure 13 and equation 4 . The effective porosity indicates the closest meaning to a quantitative vug index. Effective porosity value from 2335 stones had been quantified by Mosch and Siegesmund (2007).

$$
I_{V} \quad 10 . \frac{\phi_{e f f}}{46.2 \%}
$$

\subsection{Reservoir damage}

Formation damage is a term when a formation that is identified as a reservoir has reduction of permeability. The effect will impact well productivity. Well maximum ability to produce precious fluid will be hampered because of positif skin factors. Overbalance drilling as it is mentioned, makes a big posibility for particles of drilling fluid to go thru filter cake. After the particle go thru the filter cake barier, it may interact with materials imbedded at the formation. To quantify formation damages, only fine migration and clay swelling will be used.

Vitthal et al (1989) clay swelling index and fine migration. The index given on equation 2 , predicts how bad a formation clay can swell. The index fine-migration index on equation 5 guides to a value which describe the fine migration problems. These indices estimate the probability for particular formation damage. These indices are assigned to each clay on the basis of its distribution in the rock, its origin (authigenic or detrail), and its composition. Fine migration index uses table 1 and table 2 for input datas.

$$
\Phi_{F} \quad 100 \cdot \frac{I_{F}}{10} \cdot C F
$$

\subsection{Stuck pipe}

Overbalance method have a difference with underbalance method if considering pipe sticking. The important thing that differs from those drilling method is only differential pipe sticking. Thus differential pipe sticking has to be quatified. Sharif, Q (1997) introduces a probability function that pipe sticking will happen or not. Sharif's differential is described 1 as a definitely must happen and 0 as cannot happen. This study is based on 143 wells drilled offshore in Uni Emirate Arab.
The probability function for a particular well is determined by equation 6 and equation 7 .

SDSI $-44+0.5 \times C C+0.075 \times S O L \times E M W+0.0045 \times D_{h} \times R O P$

$P_{\text {Differential sticking }} \frac{1}{\left(1+e^{-S D S I}\right)}$

\subsection{Hard drilling}

Hard drilling conditions are experienced when drilling through dense formations with low permeability and low porosity. The implementation reason of these criteria is that it has been reported an increase in penetration rates of up to ten-fold in these formations when drilling underbalanced (Al-ajmi, 2003). Al-ajmi unfortunately did not give a objective way to quantify and classify those conditions.

The rather effective and objective way to classify a dense formation is to see these figure 10 below. Graphic from figure 10 classifies rocks based on their properties into low and high properties. For permeability properties, their are not enough data to conclude low and high properties. For practical reason a graphic (figure 12) had been made based on lost circulation event experienced by wells. This graphic is the same graphic to quantify lost circulation index. Porosity classification can be seen and generated from figure 11 . Porosity and rock density value are generated from figure 13. These three graphics are assumed to classify rocks thru through dense formations with low permeability and low porosity (or hard drilling).

\subsection{Cost benefit}

Underbalance drilling (UBD) as present is a high end technology. This will result to bigger cost regarding the additional specification of equipment and additional cost for UBD personnel. At the other hand UBD offers a great deal of benefit regarding to reducing drilling operation cost, bigger reservoir productivity, and earlier production. Spesificaly on geothermal, earlier production can not be maintained since it is a power generation activity not a producing fluid harnessing (oil/ gas). Thus any UBD planning has to compare these benefits and losts. The aim is definitely having a bigger benefit trade off if comparing with overbalance drilling project. 
Al-ajmi (2003) said additional cost on UBD related to equipments and personnel. Underbalance drilling uses air to decrease the density of the mud. This characteristic makes an obligation for UBD to install an additional equipment compared with overbalance method. Additional equipment used in safe UBD includes: rotating control head, diverter/rotating BOP, multiphase separators, compressors/boosters, nitrogen membrane unit, and specialized personnel.

A significant reduction on drilling time may add the benefit of UBD. UBD has been known to increase rate of penetration (ROP) from 2 up to 3 fold times faster. This faster drilling benefit is accelerated when minimizing non-productive time (NPT) can be implemented (example: reducing differential pipe sticking problem). Other benefit will be bits usage for 2 times longer comparing with conventional drilling method. And the last benefit is UBD prevent the loss of expensive drilling fluid. Faster ROP, minimizing NPT, longer bit life and expensive drilling fluid lost prevention may add to the benefit of UBD. UBD can minimize formation damage, thus resulting a better productivity index. On a long span of production period, a biggier produtivity index result to a much better income. Al-ajmi (2003) resume that increase ROP, minimizing NPT, longer bit life, minimizing costlydrilling fluid lost and minimizing formation damage are benefits that will gain less production cost and much more income.

\subsection{Production fluid characterisation}

Production fluid characterisation data needs water fraction / vapor fraction and $\mathrm{H}_{2} \mathrm{~S}$ gas data. These data will comply to figure 5 and figure 6 to determine which drilling fluid is compatible for certain situation. Water fraction can be known from production test results. These data include enthalpy which is usefull for detemining what quality of vapor do the production fluid has. The bigger the enthalpy, the greater chance it is to have a better vapor fraction. $\mathrm{H}_{2} \mathrm{~S}$ gas data is deliberated on geochemistry data, which is known from well test or from manifestation analysis.

\subsection{Fire}

Fire in the wellbore may happen because the drilling fluid consist air, oxygen and other flameable substances. On this figure 7 below, it shows that more air within the drilling fluid will give a bigger possibility to trigger a fire. With some certain pressure, fire will happen. Some underbalance drilling fluid has it's own advantage related to fire in the wellbore. Nitrified mud has some advantages which are: less corrosion possibility if compare with water, if oil is used as base mud then no corrosion will happen, Less down hole fire hazard. Other hazard is that underbalance drilling fluid will give more rapid corrosion activity on drilling equipments. Proper corrosion inhibitor must have to get bigger attention. Fire in the wellbore and rapid corrosion tendencies have to take in bigger consideration to make sure safety first.

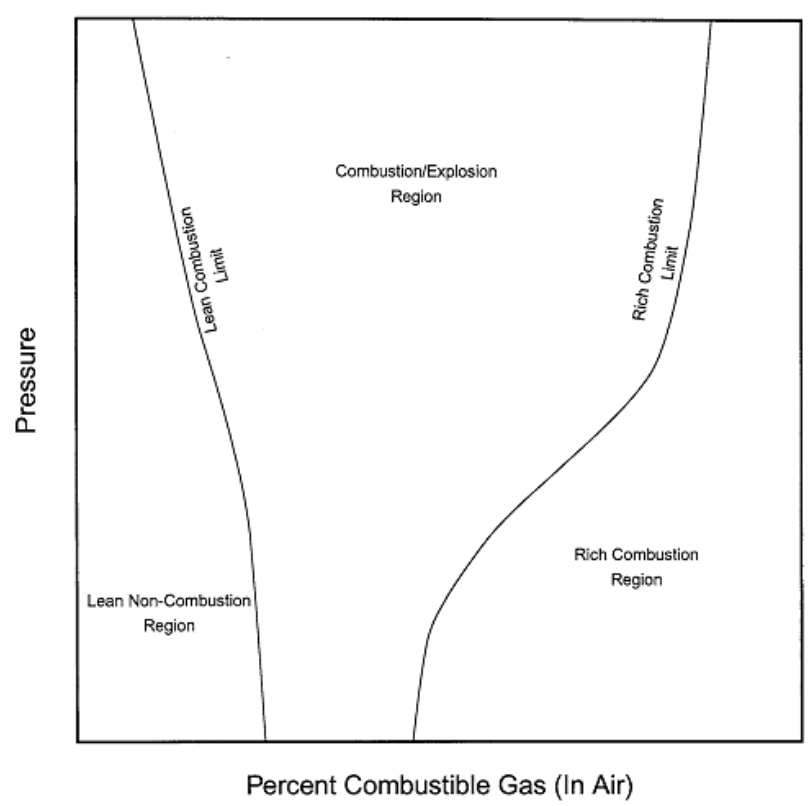

Fig. 7 Combustible flash envelope configuration at maximum circulating pressure for UBD (Bennion et. al., 1998)

\subsection{Extended reach}

Extended reach drilling is a drilling process which has more than twice longer directional section than vertical section. Drilling survey data will give information about what inclination is happening on certain depth. 


\section{Bottom hole pressure window area calculation}

To determine a bottom hole pressure window, five criteria has to be calculated (Arliyando, 2012). These criteria are:

- Pore pressure

- Bottom hole pressure

- Minimum bottom hole pressure stability

- Maximum pump rate

- Hole cleaning assessment

Pore pressure is extracted from pressure and temperature surveys at feedzone on each well. Afterward pore pressure can be looked at some future period of production time by, simulating it on a reservoir simulation process.

Minimum bottom hole pressure stability is extracted from process on section 3.1. The information is about borehole collapse pressure gradient. Then at the feedzone depth, borehole collapse pressure will be known.

Maximum pump rate is extracted from the technology available on the market. The unit that governs the limit are gallon per minute. This upper limit maximum pump rate will limit the maximum flow rate available.

\subsection{Bottom hole pressure calculation}

A bottom hole pressure is a result of the drilling mud properties and the pressure loss that occur along the conduit that a drilling mud suffer from. The drilling mud properties such as densities will give a pressure column for a given depth. And as the drilling mud go thru a sequence of conduit, it suffers from pressure loss. Pressure loss occur mainly on frictions.

A multiphase flow can be characterized as : bubbly, slug, churn and annular flow. Experiences gained from well control indicate that bubbly flow dominates the aerated mud flow in drilling operations. It is reasonable assumption that the aerated mud flow can be treated as a homogeneos mixture of liquid, gas and solid if it is flowing in bubbly regime for the purpose of pressure calculations (Guo et al., 1996). A homogeneos gives an idea that all of those three phase flow within a same velocity, thus a calculation may be more simple.

Lyon, et al. (2009) has a method of calculation for a homogeneous - aerated drilling method. The method for pressure calculation at any position is a product of pressure losses from frictions and mud column pressres. This equation 8 has to be recognized with some subtitution acting as $\mathrm{V}$ as velocity, $\mathrm{f}$ as friction factor and $\gamma_{\text {mix }}$ as mix density of the drilling fluid. The result for the subtitution is on equation 10 . A step by step iteration process is needed and can be implemented with the flow chart given on figure 14 .

$$
\begin{aligned}
& d P=\gamma_{m i x}\left[1+\frac{f V^{2}}{2 g\left(D_{b}-D_{P}\right)}\right] d h \\
& \int_{P_{e}}^{P_{b b}} \frac{d P}{B_{a}(P)}=\int_{0}^{H} d \boldsymbol{b} \\
& B_{a}(P)=\left[\frac{\dot{w}_{t}}{\left(\frac{P_{g}}{P}\right)\left(\frac{T_{a v}}{T_{g}}\right) Q_{g}+Q_{m}}\right]\left\{1+\frac{f}{2 g\left(D_{b}-D_{p}\right)}\left[\frac{\left(\frac{P_{g}}{P}\right)\left(\frac{T_{a v}}{T_{g}}\right) Q_{g}+Q_{m}}{\frac{\pi}{4}\left(D_{b}^{2}-D_{p}^{2}\right)}\right]\right\} .
\end{aligned}
$$

\subsection{Hole cleaning assessment}

Lyon et. al. (2009) said that the cleaning, lifting, and suspension capabilities of the incompressible drilling mud is generally independent of the depth of drilling. Conversely, the cleaning and lifting capabilities of compressed gas are dependent of the depth of drilling. Also, it must be noted that compressed gas drilling fluids have little or no suspension capabilities. Therefore, when designing an aerated drilling fluid, the injected compressed gas should not be assumed to contribute to bottom hole cleaning, lifting, and suspension of rock cuttings in the annulus. The additional cleaning and lifting properties of the compressed gas to the aerated drilling fluid should be considered bonuses. On this case incompressible liquid is somewhat to rely on lifting cuttings.

Figure 15 explain about steps to search minimum velocity value. It begins with calculating critical concentration velocity. The cutting concentration limit is 0.04. This value sets a maximum cutting concentration before it makes some trouble with hole cleaning. Then assuming a terminal velocity value. On this case, turbulent terminal velocity is being counted. The terminal velocity affects the flow type which is counted by a spesific reynolds number. The challenge is that on some terminal velocity number has to match on 
a result for the terminal velocity at the end. So goal seek has to be implemented on the calculation. To know the friction factor, a spherical constanta value has to be choosen. The perfect spherical will be $=1$ and a bad spherical shape will be closer to $=0$ (see figure 16 for further information). On this case, the spherical value 0.8 is choosen. Then friction factor will be known with a spesific reynolds and spherical value. After that terminal velocity can be counted. By knowing terminal velocity and critical concentration velocity, then minimum velocity can be counted.

\subsection{Bottom hole pressure window area}

Three criteria of bottom hole pressure window can be generated based on figure 17 below. The first step is to guess at what rate an underbalance drilling should be implemented. Most aerated drilling operations are planned with a constant flow rate of incompressible drilling fluid and only the volumetric flow rate of the compressed gas is allowed to vary. The volumetric flow rate of gas is usually increased as the depth is increased in order to maintain the same aerated fluid properties in the annulus column (Lyon et. al., 2009).

After calculating bottom hole pressure (BHP) at every guess gas flow rate and mud flow rate, then three graphic is made :

- Bottom hole pressure (BHP) vs Qgas graphic

- Velocity vs Qgas graphic

- Qmix vs Qgas graphic

Velocity vs Qgas graphic needs additional calculation from hole cleaning assessment and actual velocity calculation. Two graphic which are Qmix vs Qgas graphic and velocity vs Qgas graphic are the input for the bottom hole pressure (BHP) vs Qgas graphic.

Hole cleaning assessment will generate a new data series of Vminimum for a given Qgas. Another data series will be generated from actual velocity calculation. This two data series will give a different gradient thus give the possibility to intersect one and another. The intersection give a minimum ability at a certain Qgas (P) to be implemented. This Qgas (P) value then will be an input for a new bottom hole pressure calculation. The result Qgas (P) and bottom hole pressure series then are one of the criteria for the bottom hole pressure window.
A mud pump has a certain maximum ability to pump a mud. This maximum pump will generate one data series. Another data series is generated by the bottom hole pressure calculation, with Qgas and Qmix data series. This two data series will give a different gradient thus give the possibility to intersect one and another. The intersection give a maximum ability at a certain Qgas (P) to be implemented. This Qgas (P) value then will be an input for a new bottom hole pressure calculation. The result Qgas (P) and bottom hole pressure series then are one of the criteria for the bottom hole pressure window.

\section{Study case}

\subsection{Field overview}

The reservoir is a hypothetic model very simmilar to one of a high enthalpy geothermal field. This field has a maximum area is $20 \mathrm{~km}^{2}$. " $\mathrm{X}$ " geothermal field is located in a highly volcanically active. The dominant tectonic structure is a large explosion crater approximately $1 \mathrm{~km}$ wide, which on the surface is observed as a circular caldera subsidence feature, and surrounded by a tuff cone ring. This prospect area contains the large caldera lake which was produced in Plio-Pleistocene times. " $\mathrm{X}$ " geothermal prospect is located in a relatively flat depression with an average elevation of $750 \mathrm{~m}$ a.s.l. The prediction using monte carlo corelation, potential to gain electricity is for P50 probability to generate 46 Mwe for 25 years.

At this field had been drilled 8 wells so far, which consist of 2 exploration wells (X-1 and X-2), 4 production wells (X-3, X-4, X-6 and X-7) and 2 injection wells (X-5 and X-8). From pressure and temperature gradient simmilarities three reservoir cluster can be confirmed. Cluster 1 consist of X-1 and X-3. This cluster has a relatively good potential of permeability. Cluster 5 which consist of well X-5 and X-8 has not entered high temperature zone. But from the transmisivity data, it shows that these wells had not intersected much fault networks. Cluster 2 is the most potential for power generation. These wells (X-2, X-4, X-6 and X-7) have enough high temperature and good permeability to rely on. Table 4 and table 5 will give the clearest information. 
Three wells proved to produce a certain amount of vapor: X-2, X-4 and X-7 with a capacity for $5 \mathrm{MW}, 5 \mathrm{MW}$ and $12 \mathrm{MW}$ respectively. From a research their $\mathrm{Cl} / \mathrm{B}$ and $\mathrm{Cl} / \mathrm{Li}$ geochemistry ratios indicated that $\mathrm{X}-2$ and $\mathrm{X}-7$ is from a same reservoir fluid.

\subsection{Casing diameter feasibility}

The next step is to simulate the wellbore. Wellbore simulation use Hagedorn \& Brown (1965) method. The reason is that base on Hasan \& Kabir (2010) research, Hagedorn \& Brown gives the biggest R-squared result if comparing with other methods. It is expected that this method gives the least error. The simulation goes thru all of the calculation using a wellbore simulation software. Here are the results as an WHP vs Q total graphic and WHP vs enthalpy graphic. It shows a great match for the simulation results and the actual datas. (see figure 8 below). Productivity index result PI $=1.12$ $\mathrm{kg} / \mathrm{s}$. bar for X-2 and a value PI $=2.12 \mathrm{~kg} / \mathrm{s}$. bar for X7. To simplify the next step it is assumed that productivity index for $\mathrm{X}-7$ gives a close result with the future makeup well.

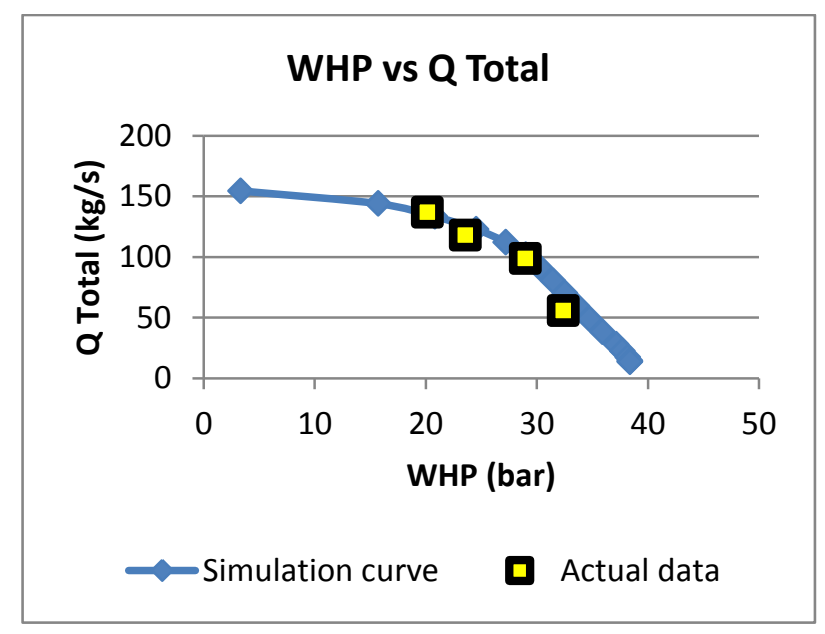

Fig 8 Wellbore simulation results for X-7

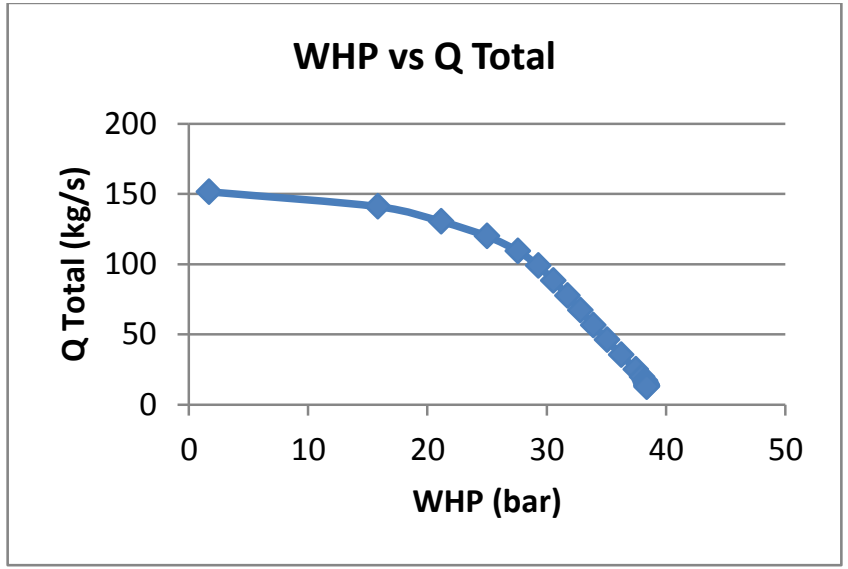

Fig 9 Wellbore simulation results for X-7 production casing 13 3/8 "

Figure 9 is the simulation result when $\mathrm{X}-7$ well is implemented with big hole production casing (casing 13 $3 / 8$ "). Then a casing diameter feasibility is conducted for several casing diameters. With a limit for liquid, 2.44 $\mathrm{m} / \mathrm{s}$ velocity in a steel pipe, then a decision for a good casing diameter implementation design can be calculated. Table 6 , table 7 and table 8 gives a best calculation picture.

\subsection{Underbalance screening process}

Figure 4 describes the flow of this decision. The black bold shapes will give the path towards underbalance decision. Based on three assessment, underbalance method has the opportunity to reduce reactive clay problems which will induce some stability issues. On a overbalance method basis, a swelling may exist from montmorillonite scattered on the clay formation. Although with some lack of rock strength data for weak formation, these stability issues have to be added some more calculation with more wellbore stability analysis. But further more, if considering that it surpasses stable rock requirement, then other assessment need to be realize. Subsequently lost circulation assessment on table 3 has showed that cluster 2 and cluster 5 have some lost possibilities. At the other part cluster 1 has severe lost possibilties. The last assessment is for reservoir damage. Reactive clay results are $28 \%$ possibility of swelling problem and $68 \%$ possibility of fine migration possibility on the reservoir area. Thus the conclusion is the reservoir is prone for reservoir damage. From all three assessment underbalance method may have the opportunity to 
reduce problem that may exist on overbalance method regardless about the lack of wellbore analysis.

Table 3

Lost circulation calculation

\begin{tabular}{lccc}
\hline Cluster & Cluster 2 & Cluster 5 & Cluster 1 \\
\hline Fracture Index & 0.75 & 3 & 2 \\
Vug Index & 3.75 & 3.75 & 3.75 \\
Porosity & 0.15 & 0.15 & 0.15 \\
Transmisivity (md) & 8.87 & 0.9 & 4.63 \\
Lost Circulation Index & 0.04 & 0.02 & 0.05 \\
Lost Circulation Possibilities & some LC & some LC & severe LC \\
\hline
\end{tabular}

From figure 5 describe the vertical wellbore drilling fluid decisions. Based on the well's pressure and temperature chart, it had been justify that " $x$ " field is a liquid dominated reservoir. On liquid dominated reservoir, liquid is the most available fluid. Casing feasibility study shows that it needs a big hole for a minimum casing production 13 3/8 ". The next criteria is water influx. It has been stated that reservoir is a liquid dominated type, thus the criteria will be definetly has water influx. The last criteria is about gas existence. The only well that give a clue about 2 phase dominated well is X-7. Another clue about gas existence is two fumarol which is located at the West side of X-1 and at the far East side of X-7. So the probability to found another two phase well is still big although with a slight fraction in fluid properties. So it is assumed that the gas existencies is not significant. At the end stiff foam or aerated mud is a final choice for vertical well with underbalance drilling method.

If a horizontal wellbore will be conducted, then figure 6 has to be implemented. The black bold shapes will give the path towards underbalance decision.

\subsection{Hole cleaning and bottom hole pressure calculation}

For hole cleaning assessment, a full scale calculation had been made with microsoft excel. The iteration uses goal seek feature on microsoft excel. This microsoft excel sheet may help other engineer to search minimum velocity for certain parameters. The result of the minimum velocity is $1.88 \mathrm{ft} / \mathrm{s}$.

A full scale bottom hole pressure calculation had been made with microsoft excel. The iteration uses goal seek feature on microsoft excel. A few calculation are made under macro-excel. This microsoft excel sheet may help other engineer to search pressure at every section and actual velocity at every section at every inner annulus area differentiations. Calculation is implemented on liquid flow rate ( $Q$ liquid) on $0.1 \mathrm{ft}^{3} / \mathrm{s}$, $0.15 \mathrm{ft}^{3} / \mathrm{s}, 0.2 \mathrm{ft}^{3} / \mathrm{s}, 0.3 \mathrm{ft}^{3} / \mathrm{s}$ and $0.4 \mathrm{ft}^{3} / \mathrm{s}$.

\subsection{Bottom hole pressure window determination}

From the X-7 well feedzone, it is concluded that the pore pressure is 1226.05 psi. With a reservoir simulation for 5 years production time a pore pressure is concluded for 1153.53 psi. This pore pressure will give an upper limit for a window area.

For this study two pumps are included. Neyrfor Weir Motor Max pump with a maximum capacity for 350 gpm and White Star Quatro $2200 \mathrm{hp}$ with a maximum capacity for 1597 gpm. These two pump will give a maximum limit on the bottom hole pressure window.

This study results are in figure 18, figure 19 and figure 20. Neyrfor Weir Motor Max pump did not give a satisfaction window area. At the other side White Star Quatro $2200 \mathrm{hp}$ gives a little window area to be implemented. The result give 2 flow rate alternatives settings:

1. Qliquid at $0.15 \mathrm{ft}^{3} / \mathrm{s}$ and a range of Qgasat 3.10 $\mathrm{ft}^{3} / \mathrm{s}-3.25 \mathrm{ft}^{3} / \mathrm{s}$

2. Qliquid at $0.10 \mathrm{ft}^{3} / \mathrm{s}$ and a range of Qgasat 2.10 $\mathrm{ft}^{3} / \mathrm{s}-3.20 \mathrm{ft}^{3} / \mathrm{s}$

On those two alternatif, care must be taken. Because the minimum bottom hole pressure collapse has not to be known yet. And alternatif one only gives a limit of underbalance diferential from pore pressure @ 5 years for around 30-50 psi. This is not an ideal condition since a bottom hole pressure fluctuation on drilling connections (Saponja, 1998) needs a minimum safety factor for connection condition for about 350 psi. If this alternatif is applied then when pipe connection, it will absolutely become overbalance. This will result mud to seep into the vugs and fracture networks. Which 
will cause problem like formation damage, pipe sticking and lost of valuable fluids.

At the second alternatif (alternatif number two) is more peferable. Considering the bottom hole pressure fluctuation on drilling connections (Saponja, 1998) addtional factor, then a range of Qliquid at $0.10 \mathrm{ft}^{3} / \mathrm{s}$ and a range of Qgas around $2.90 \mathrm{ft}^{3} / \mathrm{s}-3.20 \mathrm{ft}^{3} / \mathrm{s}$ should be implemented.

\section{Conclusion}

The conclusion is that this hypothetical field has a great chance to implement aerated underbalance drilling method. With a minimum hole cleaning assessment velocity of $1.88 \mathrm{ft} / \mathrm{s}$, two alternatif had been produced. The best alternatif is to implement a range of Qliquid at $0.10 \mathrm{ft} 3 / \mathrm{s}$ and a range of Qgas around 2.90 $\mathrm{ft}^{3} / \mathrm{s}-3.20 \mathrm{ft}^{3} / \mathrm{s}$ should be implemented.

\section{Discussion}

Wellbore stability analysis for borehole collapse pressure has absolutely need to be conducted. This analysis will help this bottom hole pressure window area research to be more reliable. An economic analysis have not been conducted. Future research can be conducted on this same reservoir for stiff foam mud. Thus need future research for these subjects.

\section{Nomenclature}

$\begin{array}{ll}\mathrm{Q} & : \text { flow rate }(\mathrm{m} 3 / \mathrm{s}) \\ \mathrm{ID} & : \text { casing inside diameter }(\mathrm{m}) \\ \mathrm{V} & : \text { fluid velocity }(\mathrm{m} / \mathrm{s}) \\ \mathrm{P} & : \text { pressure drop (bara) } \\ \rho & : \text { fluid spesific weight }\left(\mathrm{kg} / \mathrm{m}^{3}\right) \\ \mathrm{g} & : \text { gravity acceleration }\left(9.81 \mathrm{~m} / \mathrm{s}^{2}\right) ; \\ & \left(32.2 \mathrm{ft} / \mathrm{sec}^{2}\right) \\ v & : \text { fluid velocity (m/s) } \\ \mathrm{z} & : \text { well depth }(\mathrm{m}) \\ \mathrm{d} & : \text { pipe diameter }(\mathrm{m}) \\ f & : \text { friction factor }(\text { dimensionless) } \\ I_{L C} & : \text { lost circulation index }(\%) \\ k & : \text { absolute permeability (md) } \\ \phi & : \text { porosity (\%) } \\ I_{F r} & : \text { fracture index (Scale } 1-10) \\ I & : \text { vugs index (Scale } 1-10)\end{array}$

SDSI

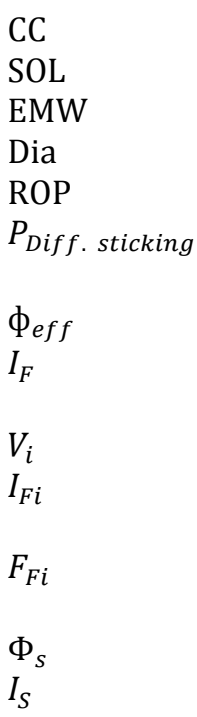

CS

$\Phi_{F}$

$C F$

$V_{\text {min }}$ or $V_{f}$

$V_{c}$

$V_{t}$

$V_{t t}$

$\gamma_{s}$

$\gamma_{f}$

$D_{c}$

$f_{p}$

$\kappa$

C

$N_{R c}$

$v$

$V_{t l}$

$\mu$

$\gamma_{\operatorname{mix}}$

$f$

V

$D_{h}$

$D_{p}$

$h$
: sharif's differential pipe sticking index

: cutting concentration (\%)

: solid percentage in drilling fluid (\%)

: effective mud weight (lb/gal)

: hole diameter (ft)

: rate of penetration $(\mathrm{ft} / \mathrm{hr})$

: differential pipe sticking probability

(\%)

: effective porosity value (\%)

: total Fine-migration Index of the

particular clay

: volume fraction of the particular clay

: fine-migration index of the particular clay.

: fine-migration factor of the particular clay.

: swelling potential

: total swelling index of the particular clay

: distribution correction factor of the particular clay for swelling.

: fine-migration potential

: distribution correction factor of the particular clay for fine-migration.

: minimum velocity $(\mathrm{ft} / \mathrm{s})$

: critical concentration velocity $(\mathrm{ft} / \mathrm{s})$

: terminal velocity $(\mathrm{ft} / \mathrm{s})$

: turbulent terminal velocity $(\mathrm{ft} / \mathrm{s})$

: cutting specific weight $\left(\mathrm{lb} / \mathrm{ft}^{3}\right)$

: fluid specific weight $\left(\mathrm{lb} / \mathrm{ft}^{3}\right)$

: cutting average diameter $(\mathrm{ft})$

: particle friction factor

(dimensionless)

: rate of penetration $(\mathrm{ft} / \mathrm{s})$

: cutting concentration (\%)

: reynolds number (dimensionless)

: kinematic viscosity $\left(\mathrm{ft}^{2} / \mathrm{s}\right)$

: laminer terminal velocity $(\mathrm{ft} / \mathrm{s})$

: dynamic / absolute viscosity

(lb.s $/ \mathrm{ft}^{2}$ )

: mix fluid specific weight $\left(\mathrm{lb} / \mathrm{ft}^{3}\right)$

: fluid friction factor (dimensionless)

: fluid actual velocity (ft/s)

: wellbore diameter $(\mathrm{ft})$

: outside pipe diameter $(\mathrm{ft})$

: depth (ft) 


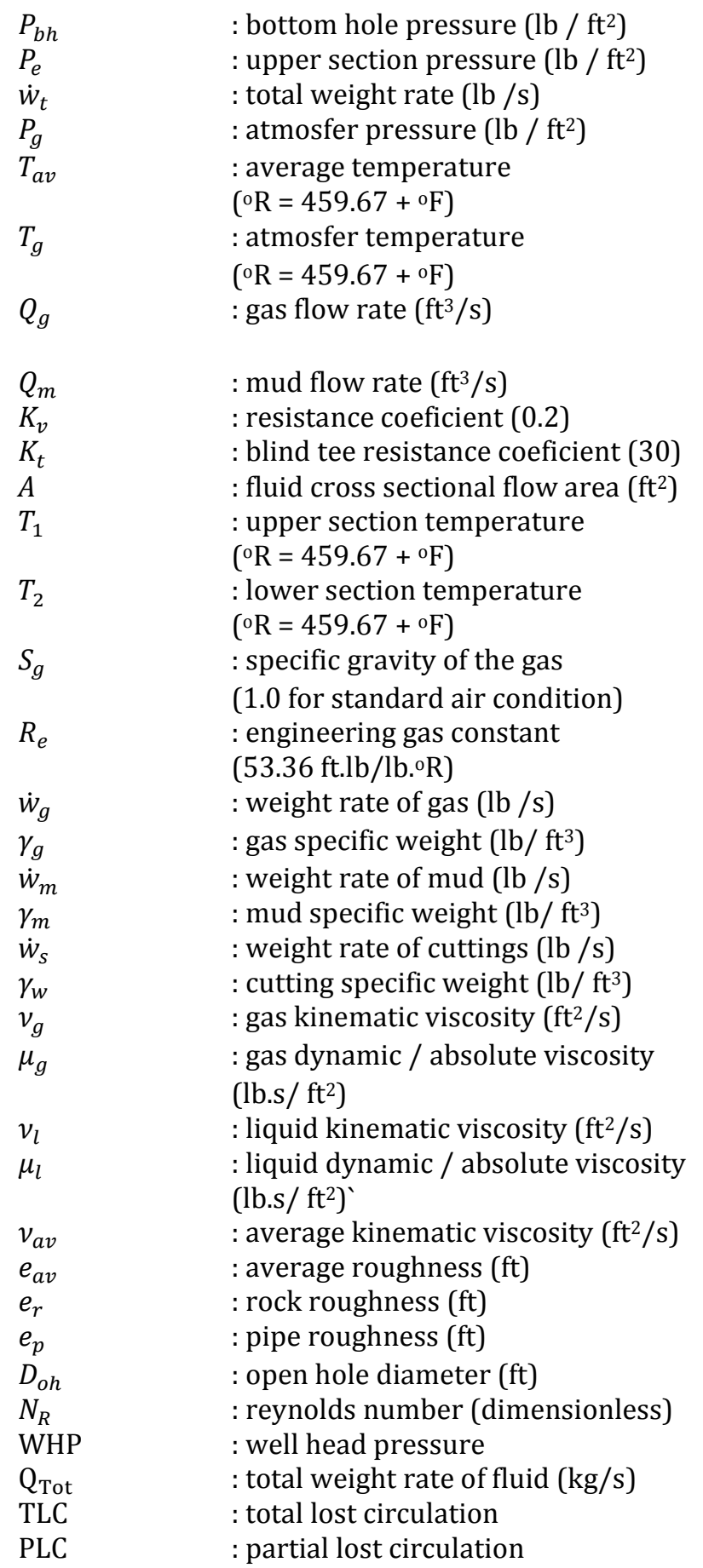

\section{Acknowledgements}

Big appreciation for all the mentors at Institut Teknologi Bandung for giving much inspiration and ideas to make this study succeed.

\section{References}

Al-Ajmi. (2003). Optimum Selection of Underbalanced Techniques. Texas: Texas A\&M University.

Arliyando, L. (2012). Feasibilitystudy of Underbalanced Drilling Using Coiled Tubing: A Case Study Field : "A", Indonesia. Bandung: ITB.

Bennion, D. B. (1998). Underbalanced Drilling And Completion Operations to Minimize Formation Damage-Reservoir Screening Criteria For Optimum Application. Journal of Canadian Petroleum Technology 37.9.

Fuh, G.-F., Whitfill, D. L., \& Schuh., P. R. (1988). Use of borehole stability analysis for successful drilling of high-angle hole. SPE/IADC Drilling Conference. SPE.

Guo, B., Hareland, G., \& Rajtar, J. (1996). Computer simulation predicts unfavorable mud rate and optimum air injection rate for aerated mud drilling. SPE Drilling \& Completion 11.2, 61-66.

Hagedorn, A. a. (1965). Experimental study of pressure gradients occurring during continuous two-phase flow in small-diameter vertical conduits. Journal of Petroleum Technology 17.4, 475-484.

Hasan, A. R. (2010). Modeling Two-Phase Fluid and Heat Flows in Geothermal Wells. Journal of Petroleum Science and Engineering 71.1, 77-86.

Hole, H. (2006). Aerated fluids for drilling of geothermal wells. United Nation University.

Lyle, 0. (1947). The efficient use of steam. HM Stationery Office.

Lyons, W. C., Guo, B., Graham, R. L., \& Hawley, G. D. (2009). Air and Gas Drilling Manual: Applications for Oil and Gas Recovery Wells and Geothermal Fluids Recovery Wells. Burlington: Elsevier.

Mosch, S., \& Siegesmund, S. (2007). Petrophysical and technical properties of dimensional stones: a statistical approach. Zeitschrift der Deutschen Gesellschaft für Geowissenschaften 158.4 , 821-868.

Saponja, J. (1998). Challenges with jointed pipe underbalanced operations. SPE drilling \& completion 13.2, 121-128. 
Sharif, Q. (1997). A Case Study of Stuck Pipe Problems and Development of Statistical Models to Predict the Probability of Ge tting Stuck and IF Stuck, The Probability of Getting Free. Texas: Texas A\&M University.

Vitthal, S., Gupta, A., \& Sharma, M. (1989). A RuledBased System for Estimating Clay Distribution, Morphology, and Formation Damage in Reservoir Rocks. SPEFE. 


\section{Appendix}

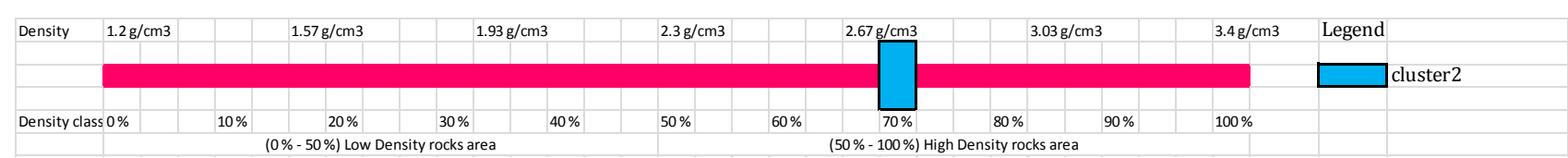

Fig 10 Rock density classification; Andesit / basalt rock on cluster 2 is classified as high density rock

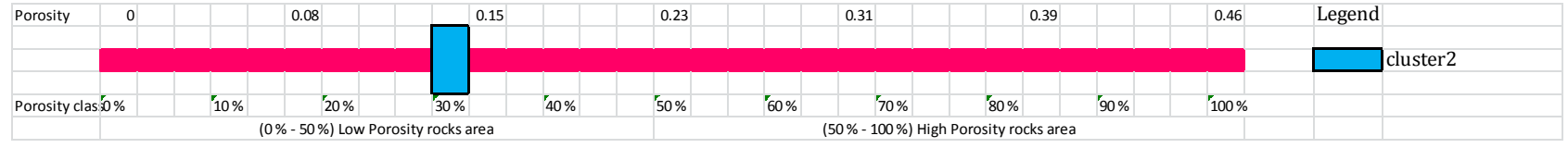

Fig 11 Rock porosity classification; Andesit / basalt rock on cluster 2 is classified as low porosity rock

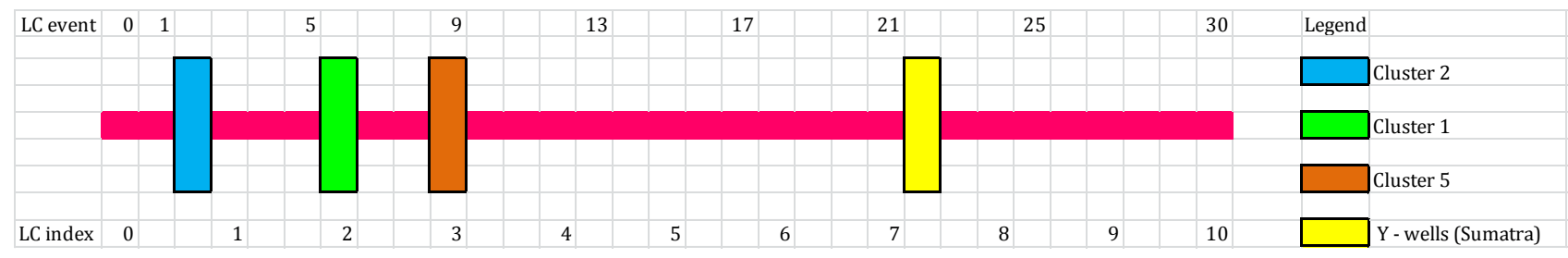

Fig 12 Lost circulation classification; Cluster 2 rock is classified as low fractured rock thus low permeability 


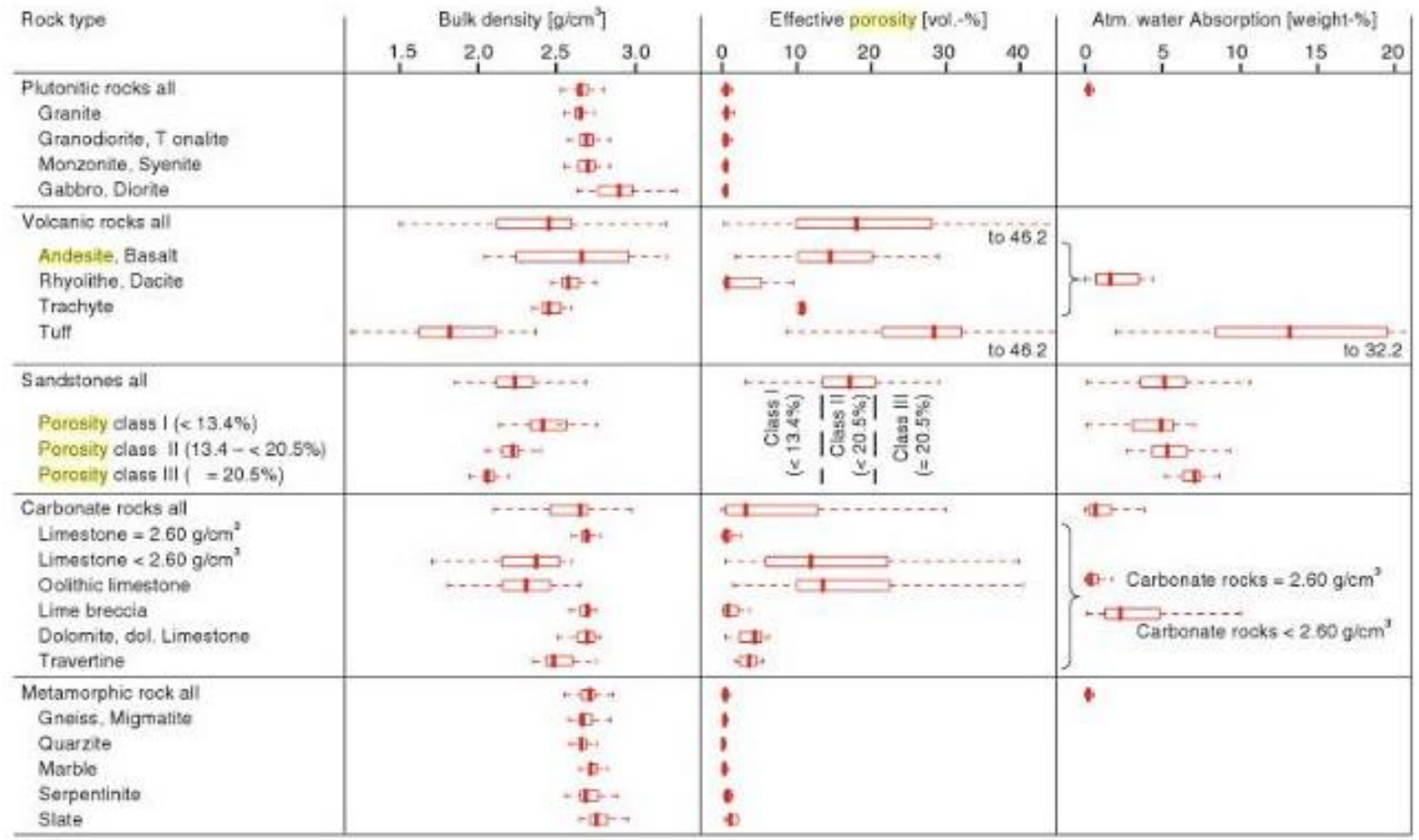

Fig 13 Bulk density, effective porosity and water absorption on each rock types. Based on 2335 stones (Mosch and Siegesmund, 2007) 


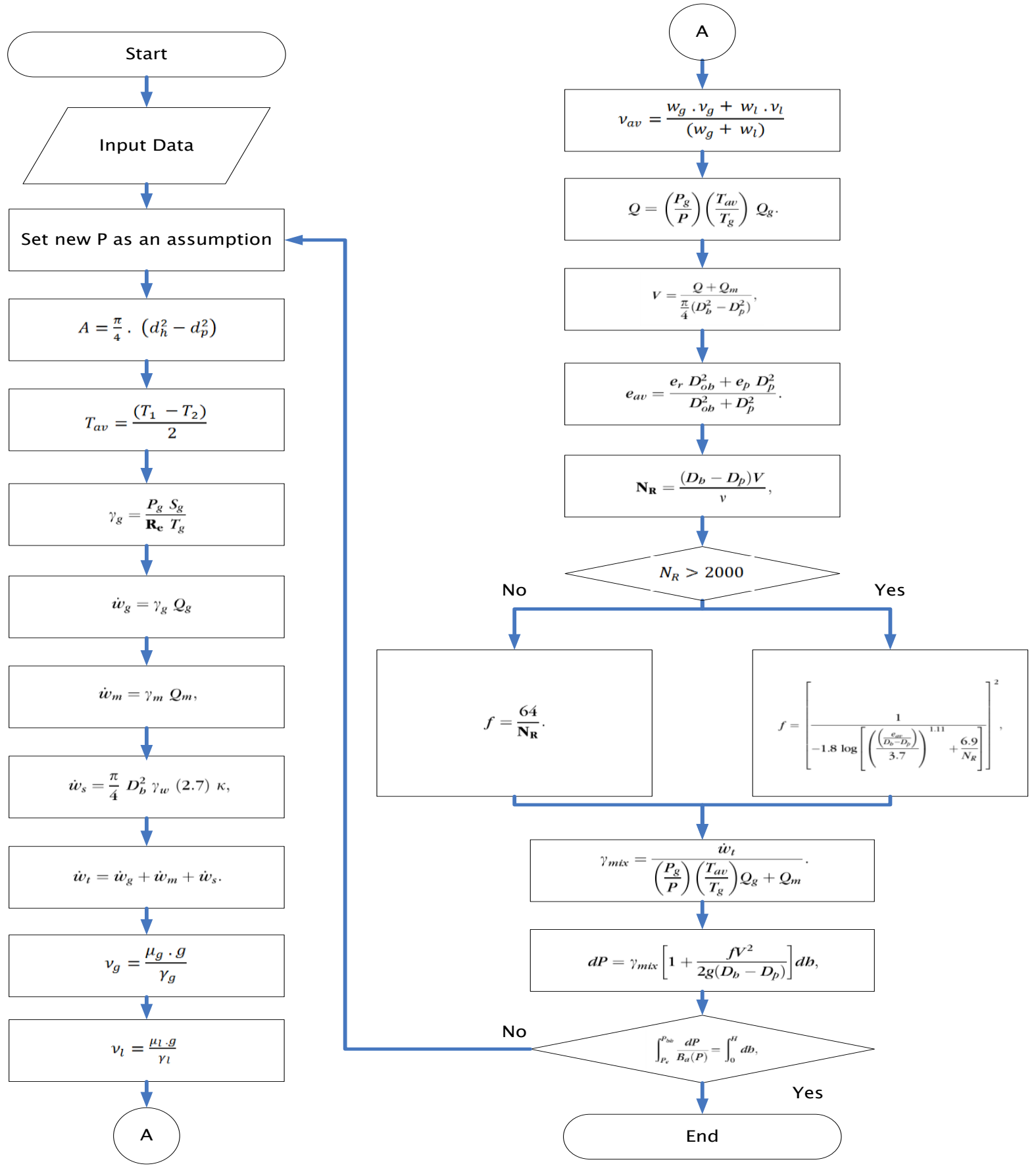

Fig 14 Bottom hole pressure calculation flow chart (Lyon et. al., 2009) 
Ariya Dwinanto et al. / KnE Energy (2015) 22-46

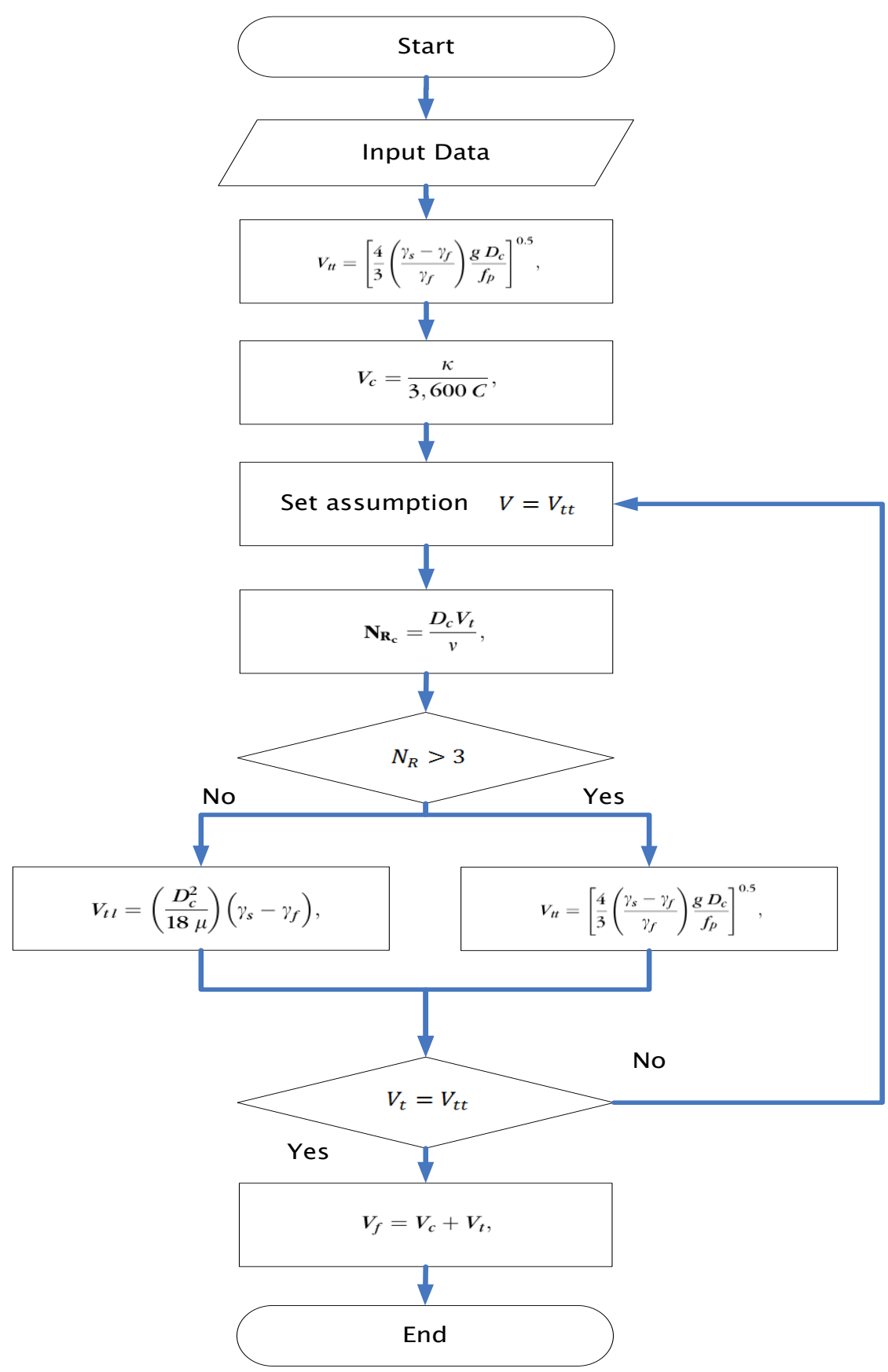

Fig 15 Lyon et. al. (2009) hole cleaning method 


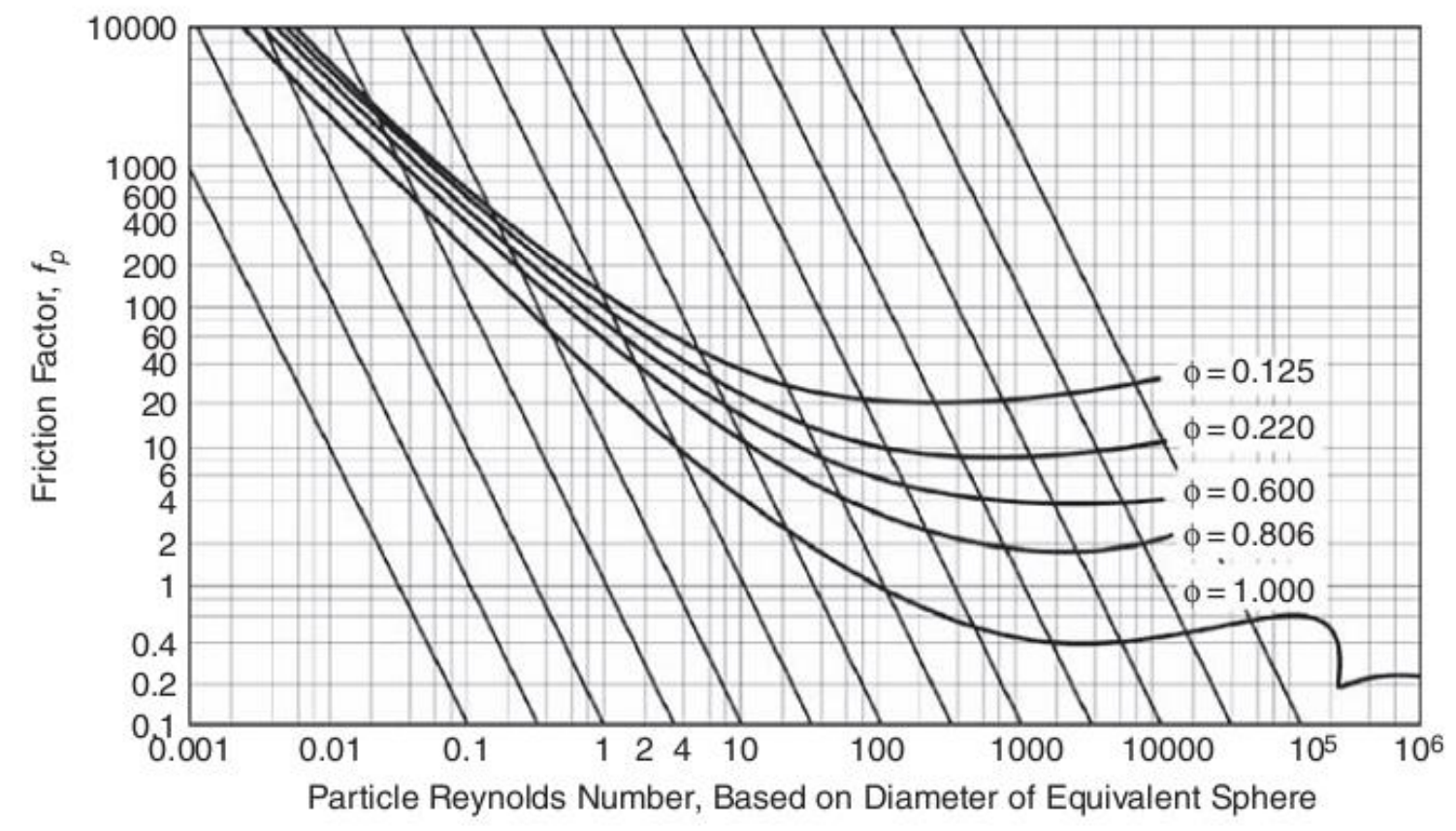

Fig 16 Particle friction factor diagram (Lyon et. al.,2009) 


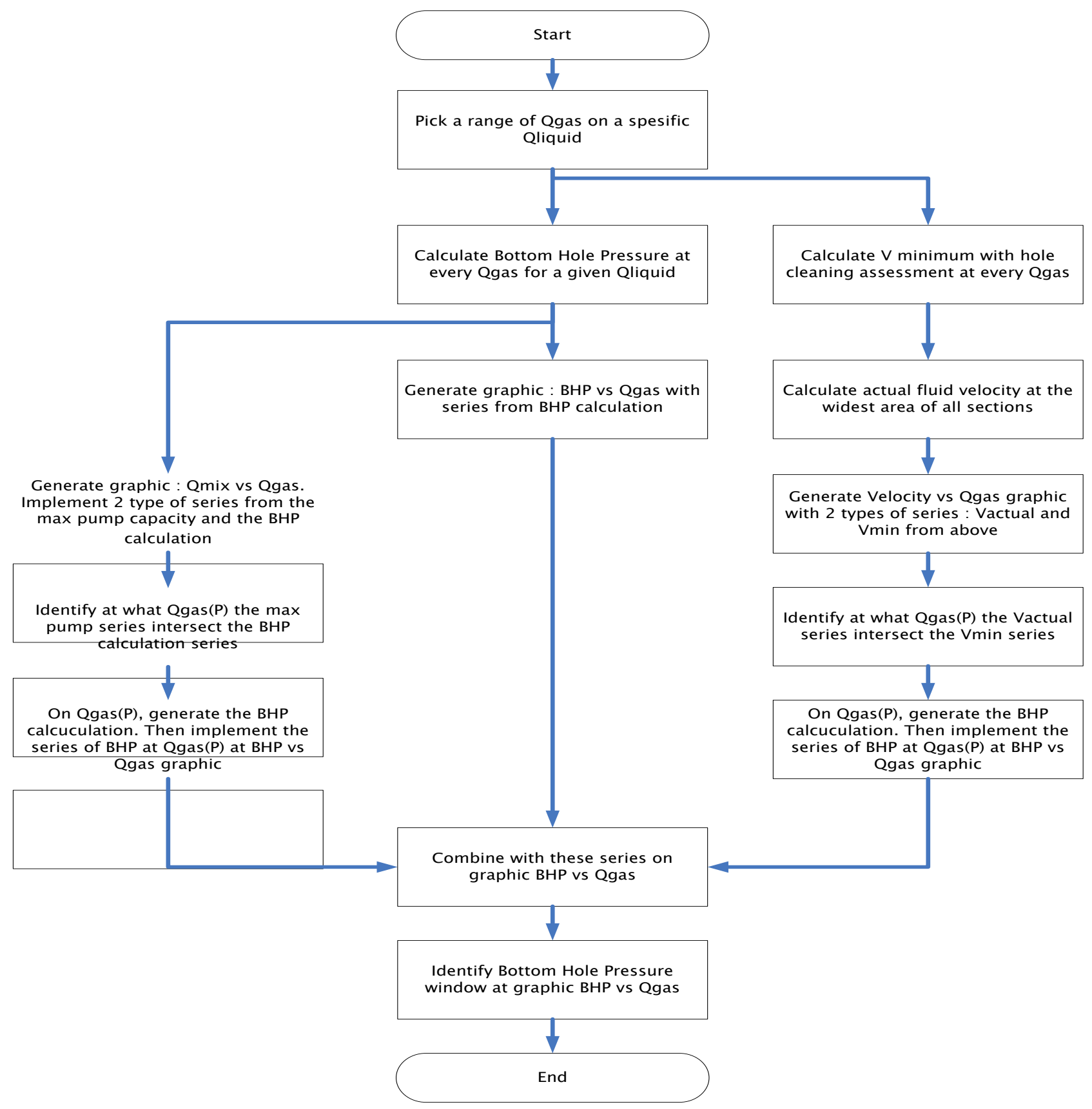

Fig 17 Bottom hole pressure window area determination 
Table 4

Reservoir characteristic cluster-1 and cluster-5

\begin{tabular}{lcccc}
\hline & \multicolumn{2}{c}{ Cluster - 1 } & & Cluster - 5 \\
\hline Well & X-1 & X-3 & X-5 & X-8 \\
\hline $\begin{array}{l}\text { Reservoir type } \\
\text { Reservoir } \\
\text { temperature }\end{array}$ & Water & Water & Water & Water \\
$\begin{array}{l}\text { Transmisivitas } \\
\text { (kh), Darcy.m }\end{array}$ & $225-250^{\circ} \mathrm{C}$ & $225-300^{\circ} \mathrm{C}$ & $225^{\circ} \mathrm{C}$ & $225^{\circ} \mathrm{C}$ \\
$\begin{array}{l}\text { Skin } \\
\text { Well depth }\end{array}$ & $\mathrm{n} / \mathrm{a}$ & 4.63 & 0.9 & 0.23 \\
$\begin{array}{l}\text { Total loss } \\
\text { circulation (TLC) }\end{array}$ & $-1142 \mathrm{mrsl}$ & -0.04 & $\mathrm{n} / \mathrm{a}$ & $\mathrm{n} / \mathrm{a}$ \\
& $\mathrm{no}$ TLC & $-1122 \mathrm{mrsl}$ & $-1050 \mathrm{mrsl}$ & $-1081 \mathrm{mrsl}$ \\
$\begin{array}{l}\text { Partial loss } \\
\text { circulation (PLC) }\end{array}$ & $-26 \mathrm{mrsl} ;-35 \mathrm{mrsl} ;$ & $-879 \mathrm{mrsl} ;-894 \mathrm{mrsl} ;$ & $-219 \mathrm{mrsl}$ to $-372 \mathrm{mrsl} ;$ & No TLC \\
& $-48 \mathrm{mrsl} ;-694 \mathrm{mrsl} ;$ & $-945 \mathrm{mrsl} ;-1020 \mathrm{mrsl} ;$ & $-418 \mathrm{mrsl}$ to $-1014 \mathrm{mrsl} ;$ & $-922 \mathrm{mrsl}$ \\
\hline
\end{tabular}

Table 5

Reservoir characteristic cluster-2

\begin{tabular}{lcccc}
\hline \multicolumn{1}{c}{ Cluster - 2 } & & \\
\hline Well & X-2 & X-4 & X-6 & X-7 \\
\hline $\begin{array}{l}\text { Reservoir type } \\
\begin{array}{l}\text { Reservoir } \\
\text { temperature }\end{array}\end{array}$ & Water & Water & Water & two phase \\
$\begin{array}{l}\text { Transmisivitas (kh), } \\
\text { Darcy.m }\end{array}$ & $260^{\circ} \mathrm{C}$ & $225-255^{\circ} \mathrm{C}$ & $257^{\circ} \mathrm{C}$ & $250-270^{\circ} \mathrm{C}$ \\
$\begin{array}{l}\text { Skin } \\
\text { Well depth }\end{array}$ & $\mathrm{n} / \mathrm{a}$ & 7.12 & $\mathrm{n} / \mathrm{a}$ & 8.87 \\
$\begin{array}{l}\text { Total loss } \\
\text { circulation (TLC) }\end{array}$ & $-800 \mathrm{mrsl}$ & -1.67 & $\mathrm{n} / \mathrm{a}$ & $\mathrm{n} / \mathrm{a}$ \\
& $-400 \mathrm{mrsl}$ & $-1000 \mathrm{mrsl}$ & $-1019 \mathrm{mrsl}$ & $-714 \mathrm{mrsl}$ \\
$\begin{array}{l}\text { Partial loss } \\
\text { circulation (PLC) }\end{array}$ & $-144 \mathrm{mrsl} ;-360 \mathrm{mrsl} ;$ & $-400 \mathrm{mrsl}$ & $-280 \mathrm{mrsl}$ and & $-200 \mathrm{mrsl}$ \\
& & $-389 \mathrm{mrsl}$ & $-550 \mathrm{mrsl}$ & $-194 \mathrm{mrsl}$ \\
\hline
\end{tabular}


Table 6

Casing diameter feasibility study (13 3/8 ")

Casing Production 13 3/8 "

\begin{tabular}{|c|c|c|c|c|c|c|c|c|}
\hline $\begin{array}{l}\text { Well } \\
\text { Head }\end{array}$ & $\begin{array}{l}\text { Weight } \\
\text { Flow } \\
\text { Rate }\end{array}$ & $\begin{array}{l}\text { Saturated Water } \\
\text { Spesific Volume }\end{array}$ & $\begin{array}{l}\text { Flow } \\
\text { Rate }\end{array}$ & & ing proper & & $\begin{array}{l}\text { Velocity } \\
\text { of liquid }\end{array}$ & Result \\
\hline bar & $\mathrm{kg} / \mathrm{s}$ & $\mathrm{m} 3 / \mathrm{kg}$ & $\mathrm{m} 3 / \mathrm{s}$ & ID (inch) & A (inch2) & $A(m 2)$ & $\mathrm{m} / \mathrm{s}$ & \\
\hline 16 & 140 & 0.00 & 0.17 & 12.25 & 117.86 & 0.08 & 2.24 & Approved \\
\hline
\end{tabular}

Table 7

Casing diameter feasibility study (10 3/4 ")

Casing Production 10 3/4 "

\begin{tabular}{ccccccccc}
\hline $\begin{array}{c}\text { Well } \\
\text { Head } \\
\text { Pressure }\end{array}$ & $\begin{array}{c}\text { Weight } \\
\text { Flow } \\
\text { Rate }\end{array}$ & $\begin{array}{c}\text { Saturated Water } \\
\text { Spesific Volume }\end{array}$ & $\begin{array}{l}\text { Flow } \\
\text { Rate }\end{array}$ & Casing properties & $\begin{array}{c}\text { Velocity } \\
\text { of liquid }\end{array}$ & Result \\
\hline (bar) & $\mathbf{( k g / s )}$ & $\mathbf{V ~ ( m 3 / k g )}$ & $\mathbf{m 3} / \mathbf{s}$ & ID (inch) & A (inch2) & A (m2) & m/s & \\
\hline 16 & 140 & 0.00 & 0.17 & 9.56 & 71.78 & 0.05 & 3.68 & $\begin{array}{c}\text { Bad } \\
\text { Design }\end{array}$ \\
\hline
\end{tabular}

Table 8

Casing diameter feasibility study (7 ")

Casing Production 7 "

\begin{tabular}{|c|c|c|c|c|c|c|c|c|}
\hline \multirow{2}{*}{$\begin{array}{c}\begin{array}{c}\text { Well } \\
\text { Head } \\
\text { Pressure }\end{array} \\
\text { (bar) }\end{array}$} & \multirow{2}{*}{$\begin{array}{c}\text { Weight } \\
\text { Flow } \\
\text { Rate }\end{array}$} & \multirow{2}{*}{$\begin{array}{c}\text { Saturated Water } \\
\text { Spesific Volume } \\
\text { V (m3/kg) }\end{array}$} & \multirow{2}{*}{$\begin{array}{l}\text { Flow } \\
\text { Rate } \\
\mathrm{m} 3 / \mathrm{s}\end{array}$} & \multicolumn{3}{|c|}{ Casing properties } & \multirow{2}{*}{$\begin{array}{c}\text { Velocity } \\
\text { of liquid }\end{array}$} & \multirow[t]{2}{*}{ Result } \\
\hline & & & & ID (inch) & A (inch2) & $A(m 2)$ & & \\
\hline 16 & 105 & 0.00 & 0.13 & 5.92 & 27.53 & 0.02 & 7.20 & $\begin{array}{c}\text { Bad } \\
\text { Design }\end{array}$ \\
\hline
\end{tabular}




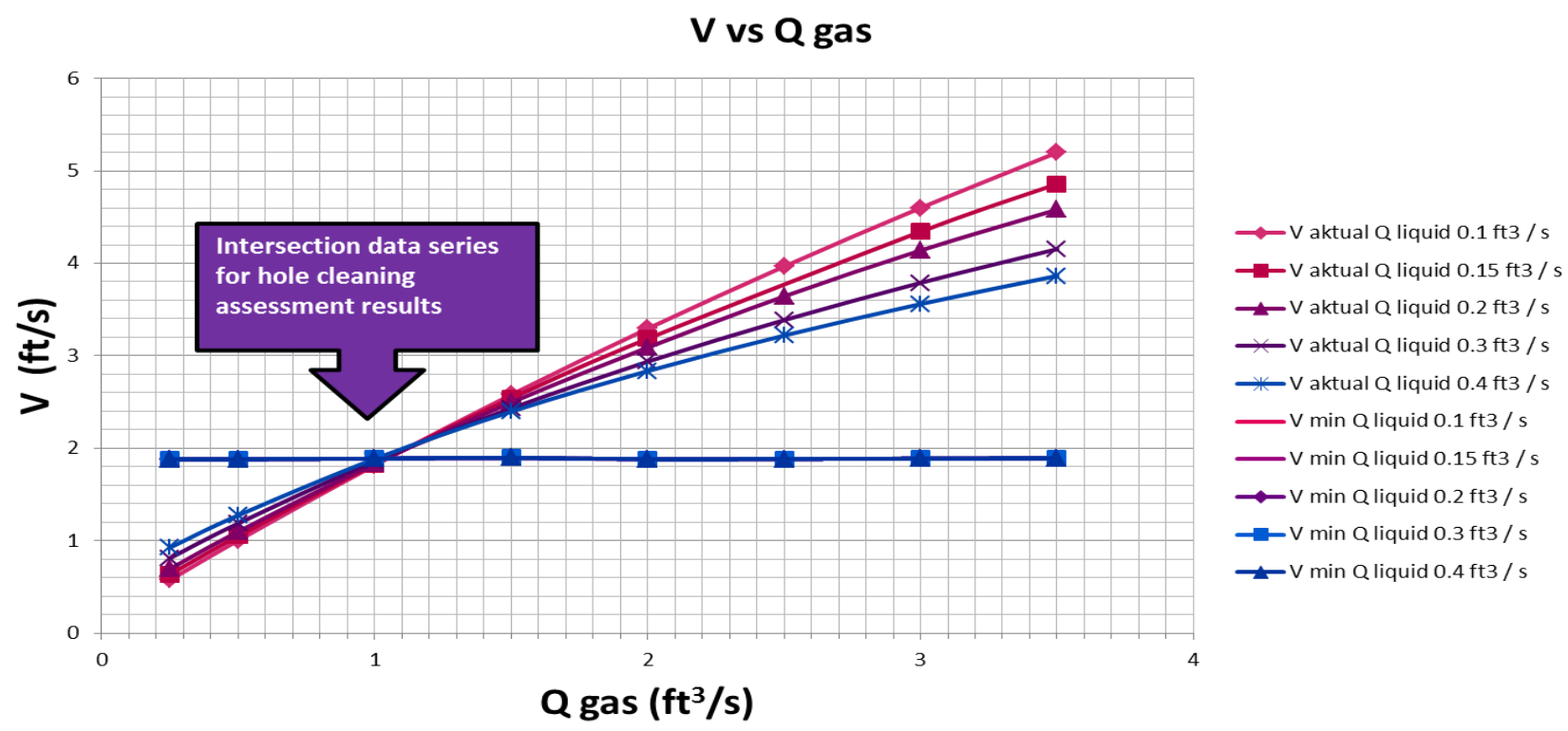

Fig 18 Velocity (V) vs Gas flow rate (Q gas) graphic

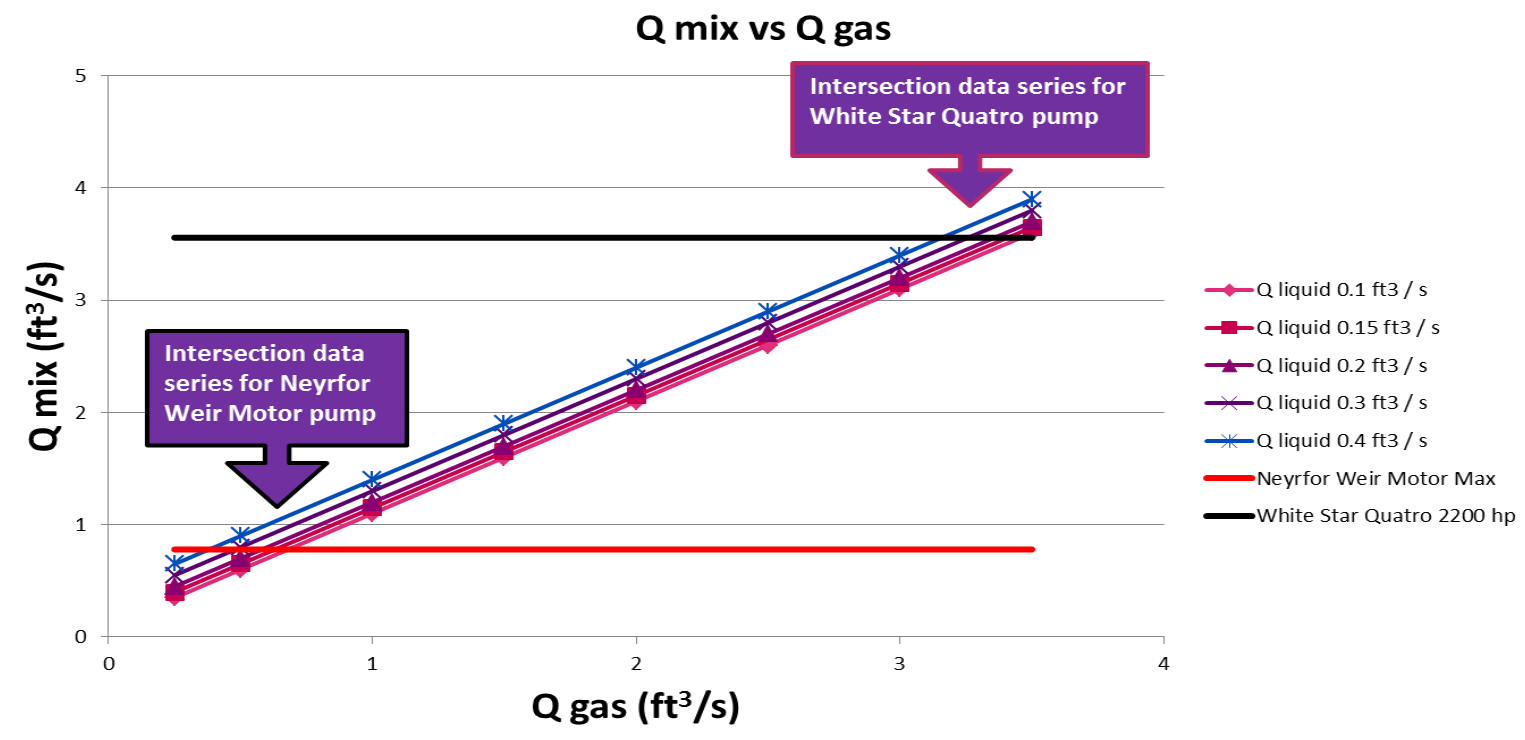

Fig 19 Mix flow rate (Q mix) vs Gas flow rate ( $Q$ gas) graphic 


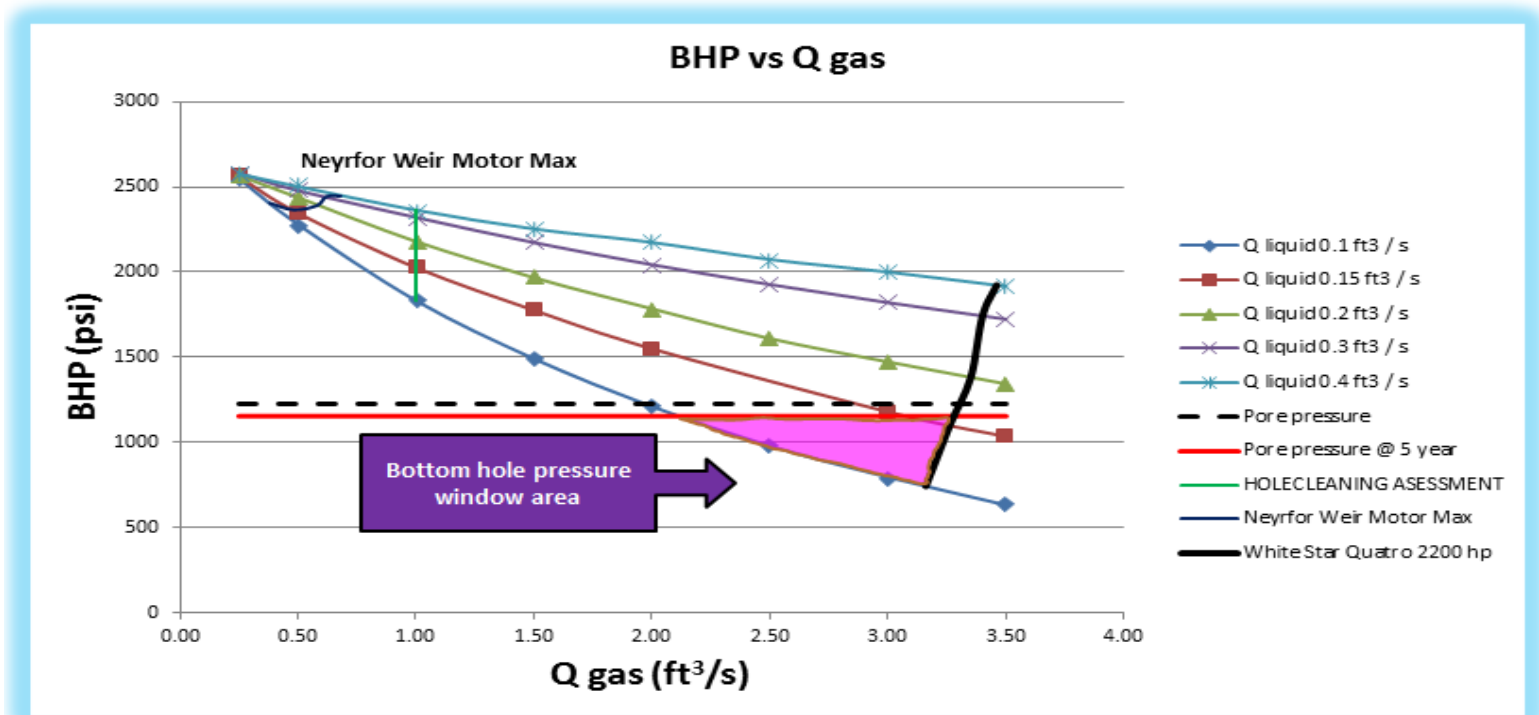

Fig 20 Bottom hole pressure (BHP) vs Gas flow rate (Q gas) graphic 